\title{
Tribological Properties of 2D Materials and Composites-A Review of Recent Advances
}

\author{
Bodhi R. Manu, Anju Gupta and Ahalapitiya H. Jayatissa *
}

Citation: Manu, B.R.; Gupta, A.; Jayatissa, A.H. Tribological Properties of 2D Materials and Composites-A Review of Recent Advances. Materials 2021, 14, 1630. https://doi.org/ $10.3390 / \mathrm{ma} 14071630$

Academic Editor: Ludwig Cardon

Received: 16 January 2021

Accepted: 20 March 2021

Published: 26 March 2021

Publisher's Note: MDPI stays neutral with regard to jurisdictional claims in published maps and institutional affiliations.

Copyright: (c) 2021 by the authors. Licensee MDPI, Basel, Switzerland. This article is an open access article distributed under the terms and conditions of the Creative Commons Attribution (CC BY) license (https:/ / creativecommons.org/licenses/by/ $4.0 /)$.
Mechanical Industrial and Manufacturing Engineering (MIME) Department, University of Toledo, Toledo, OH 43606, USA; bodhi.ravindranmanu@rockets.utoledo.edu (B.R.M.); anju.gupta@utoledo.edu (A.G.)

* Correspondence: ahalapitiya.jayatissa@utoledo.edu

\begin{abstract}
This paper aims to provide a theoretical and experimental understanding of the importance of novel 2D materials in solid-film lubrication, along with modulating strategies adopted so far to improve their performance for spacecraft and industrial applications. The mechanisms and the underlying physics of 2D materials are reviewed with experimental results. This paper covers some of the widely investigated solid lubricants such as $\mathrm{MoS}_{2}$, graphene, and boron compounds, namely h-BN and boric acid. Solid lubricants such as black phosphorus that have gained research prominence are also discussed regarding their application as additives in polymeric materials. The effects of process conditions, film deposition parameters, and dopants concentration on friction and wear rate are discussed with a qualitative and quantitative emphasis that are supported with adequate examples and application areas and summarized in the form of graphs and tables for easy readability. The use of advanced manufacturing methods such as powder metallurgy and sintering to produce solid lubricants of superior tribological performance and the subsequent economic gain from their development as a substitute for liquid lubricant are also evaluated.
\end{abstract}

Keywords: 2D materials; tribology; thin films; solid lubricants

\section{Introduction}

Friction is a necessary evil. Friction between the ground and shoes enables walking; however, the friction between the mechanical and electrical components decreases the overall efficiency of their constituting systems [1-4]. Around $20 \%$ of the world energy production is utilized toward overcoming friction [5]. The first documented study of friction was conducted by Thermistius in $350 \mathrm{BC}$ and demonstrated that the rolling friction is less than the sliding friction due to the torque generated by frictional force that assists against friction $(\mu \mathrm{k}<\mu \mathrm{s})[6]$. The study of friction requires correlation between theoretical concept, experimental, and numerical investigations, which remain unaddressed. The term tribology was coined in 1960 to connect the three important interdisciplinary fields of research, namely friction, lubrication, and wear. The economic impact of frictional losses was the impetus for eventually connecting these different branches under a common umbrella [7]. This is also critical in expanding the knowledge and filling in the gaps in the literature. Most of the reported literature is experimental in nature, including shared methodologies and original data that further provide novel insights on friction control, the reduction of frictional losses, and a better understanding the mechanisms.

Liquid lubricants are widely used in most industrial applications such as in automobiles and manufacturing industries. Liquid lubricants consist of a base polymer with additives added. The additives provide lubrication, whereas the polymer base provides dispersion and stability to the additives. The additives are very sensitive to the working conditions such as load, speed, and temperature; the viscosity and design of the lubricating system is also important. A good lubricating system design should be able to provide adequate pressure difference for the flow of liquids polymers to the required parts based on viscosity. The narrow range of effective working spectrum and complexity of designing 
to provide pressure difference for lubricant flow makes it difficult for the use of liquid lubricants in extreme working conditions where temperature of pressure varies substantially or there is the presence of gases and radiations that can react with the lubricant, deteriorating its lubricating property system $[8,9]$.

The solid lubricants were primarily developed for applications where liquid lubricants are inadequate such as in aircraft and space exploration, which is characterized by extreme surrounding conditions in outer space, such as temperature variation during the day, intensity of solar radiations, atmospheric pressure, and atmospheric gasses [10]. Under these conditions, liquid lubricants are inadequate both from the standpoint of stable additive and design constrains. However, very few solid lubricants are used in industrial applications to reduce wear, such as coatings on rollers and balls of antifriction bearings and engine piston assembly. Metal nanocomposite and diamond-like carbon (DLC) coatings are mostly used for these applications.

Graphite is one of the earliest elements used as a solid lubricant or as an additive in liquid lubricants, which further led to an investigation of materials with similar crystal structure as graphite, now known as two-dimensional (2D) materials. These materials are mostly used in solid lubricants and preferred over metals and alloys as they provide easy sliding between the atomic layers and hence provide low friction. $\mathrm{MoS}_{2}, \mathrm{~h}-\mathrm{BN}$, and boric acid are some of the successful solid lubricants that fall into this category [11-13]. The layered structure of 2D materials is responsible for the materials' lubricating property in which each layer of these materials is covalently bonded to each other layer through $\mathrm{sp}^{2}$ or $\mathrm{sp}^{3}$ hybridization, resulting in stronger bonds. This strong interlayer bonding results in 2D materials that are stronger, stiffer, and harder [14,15]. Few 2D materials, such as $\mathrm{WS}_{2}$ graphene, possess very low friction coefficients but are susceptible to high wear [16]. In contrast, transition metal oxides, h-BN, and nitrocarbons have superior wear-resistance but a higher friction coefficient $[17,18]$. This contradictory behavior among the 2D materials is due to the nature of intralayer bonding between each atomic layer. In case of the $2 \mathrm{D}$ materials with a very low friction coefficient, the layers are attracted to each other by weak Van der Waals forces, which provides easy sliding between the layers that reduce the friction. On the other hand, 2D metal oxides usually have a hexagonal wurtzite or tetragonal structure in which the interlayer atoms are bonded to each other by covalent bonds, which cause high intralayer friction but reduce wear as it restricts cleavage between layers. With an increase in intralayer bond strength, the coefficient of friction also increases, but the wear on 2D materials decreases.

In this comprehensive review, carbon-based solid lubricants such as graphite, graphene, transition metal di-sulfides, and di-selenides such as $\mathrm{MoS}_{2}$ and $\mathrm{WSe}_{2}$, boron-based compounds -h-BN and boric acid, black phosphorous, and ceramic materials such as $\mathrm{ZnO}$ are discussed and summarized in Figure 1 [19-21]. A schematic of the relative percentage of publications on these 2D materials is also shown in Figure 2. Among these 2D materials, $\mathrm{MoS}_{2}$ and carbon-based compounds including graphite and graphene are the most investigated materials. $\mathrm{MoS}_{2}$ is the most successful solid lubricant for aerospace applications in dry conditions, whereas graphite and some other carbon-based lubricants require a humid environment to provide good lubrication [22]. The discovery of graphene and its desirable electronic and tribological properties have led to a detailed investigation on nano- and micro-scale friction for its applications in MEMS/NEMS devices [23,24]. These investigations have provided a deeper insight into friction mechanisms and energy dissipation on an atomic level. 


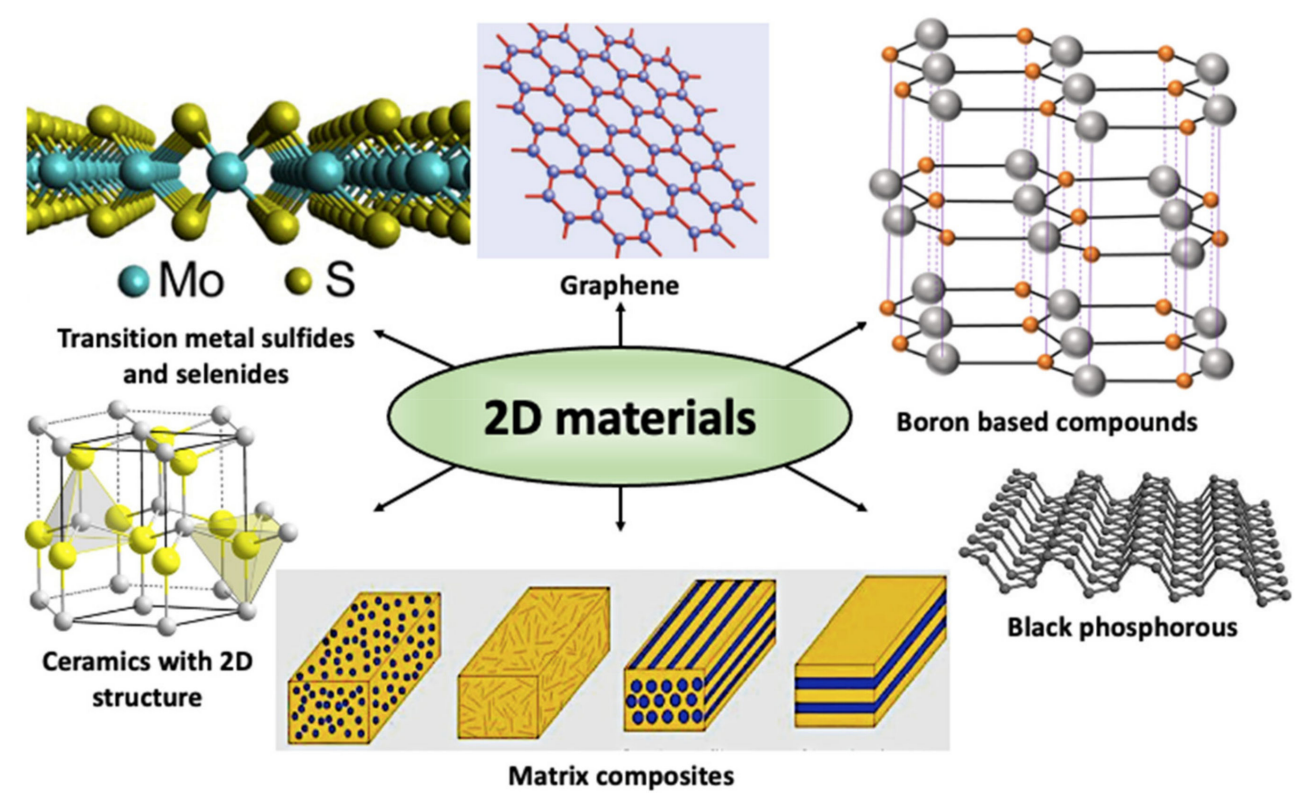

Figure 1. Schematic of different 2D materials covered in this review [19-21].

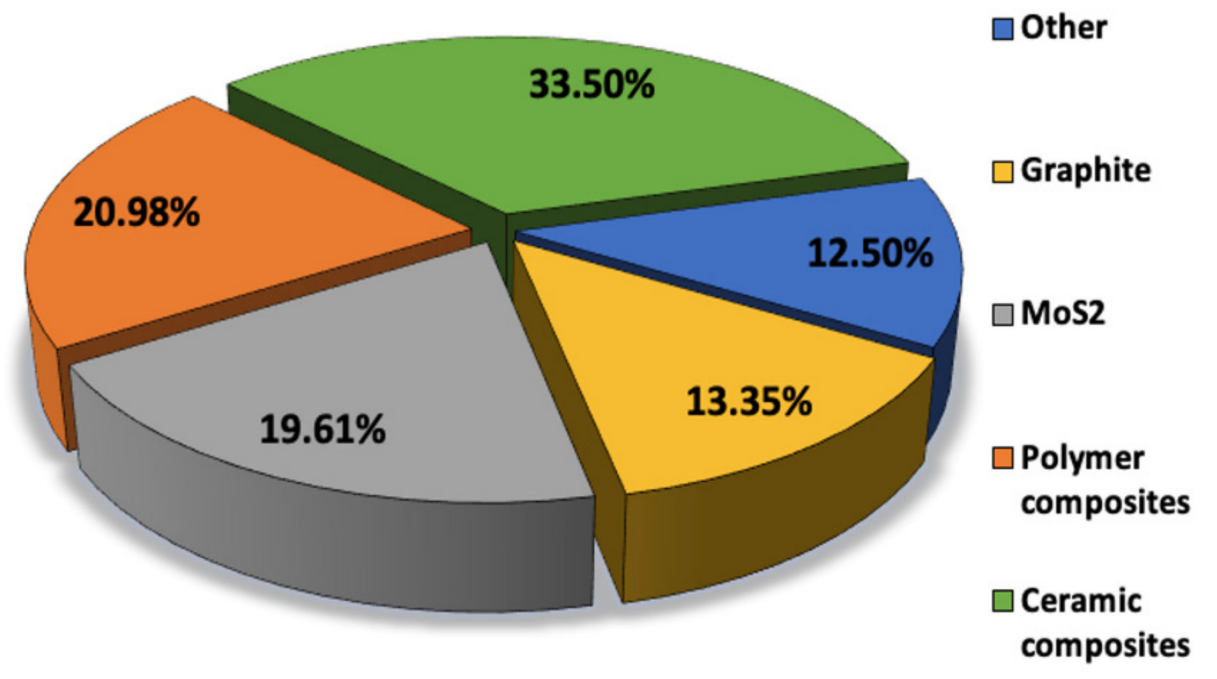

Figure 2. The pie chart shows the research conducted on different solid lubricants from 2000 to 2020; source: Web of Science database, 2000 to 2020. Keywords used in the search: Title = ("solid lubricant" OR "solid-lubricant composite" OR "self-lubricating solid lubricant" OR "polymer, ceramic, and metal matrix composites" and "tribological properties" OR "friction" OR "wear" OR "antifriction") AND Topic = ("powder metallurgy" OR "compression molding" OR "sintering" OR “UV curing"). The total number of publications analyzed equals 334 .

\section{Mechanisms of Frictional Energy Dissipation on an Atomic Scale}

Friction at the macroscale is quantified in terms of coefficient of friction and the wear rate. For efficient control of frictional losses, it is important to understand the underlying atomistic mechanisms of frictional losses. Friction results from heat generated due to various physical, mechanical, and chemical interactions occurring at the interface of the sliding surfaces [25-27]. However, the complexity of the interactions and the unavailability of a single theoretical model make it impossible to quantify the relative contributions made by each of these interactions. In this section, various known mechanisms underlying heat generation at atomic scale due to sliding are examined to provide a theoretical insight on friction as summarized schematically in Figure 3. 


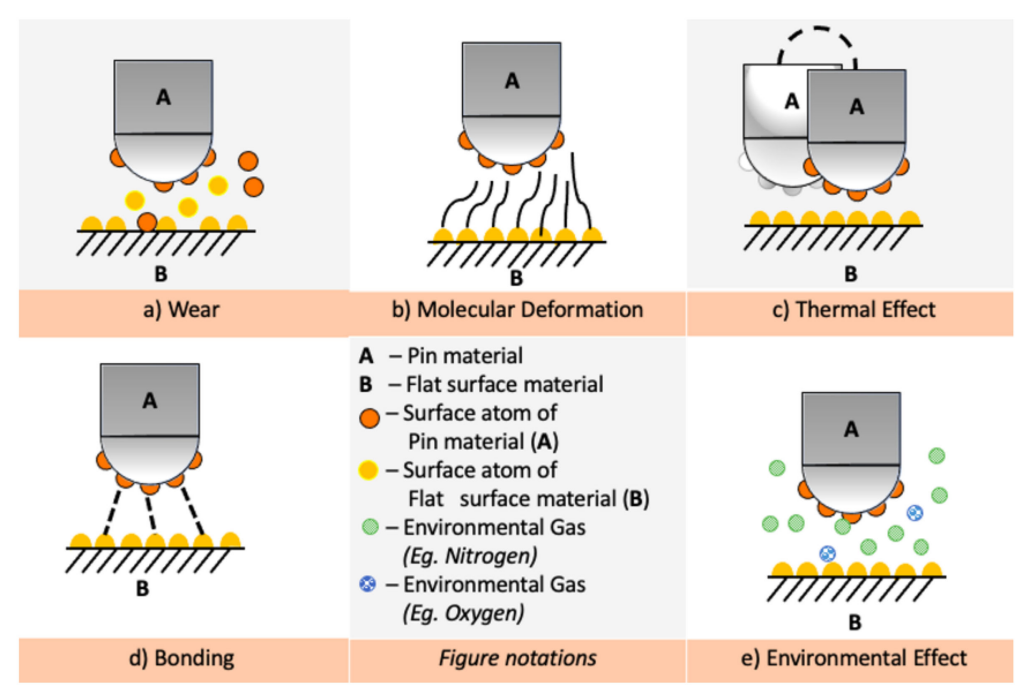

Figure 3. Different microscale mechanisms of frictional energy dissipation: (a) Wear mechanism; (b) Molecular deformation; (c) Thermal Effect; (d) Bonding; and (e) Environmental effect [28].

\section{(a) Wear}

At macroscale, wear is caused by plastic deformation and fracture of the solid-film materials, which leads to physical damage. Wear makes the surface rougher and further leads to an increase in friction. For solid-film lubrication, it is desirable to have the film undergo ductile deformation rather than brittle fracture. Ductile materials undergo plastic deformation by the movement of dislocations, and it can be controlled by tailoring of grain size and grain orientation. On the other hand, brittle fracture is promoted by crack initiation, and propagation that will lead to a higher wear rate after the onset of the wear phenomenon. The wear debris formed also assists in additional wear especially in the case of brittle films [29-31].

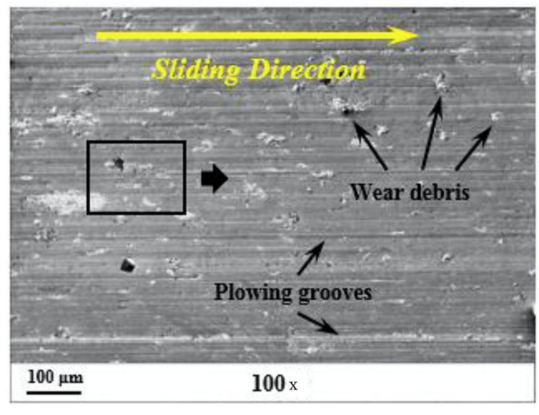

(a)

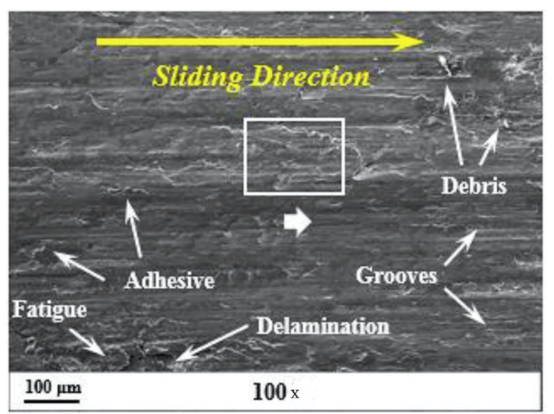

(c)

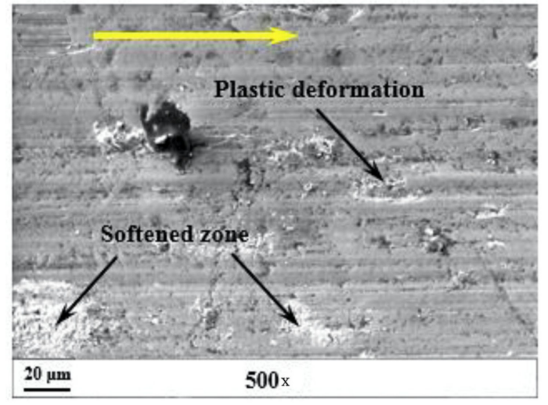

(b)

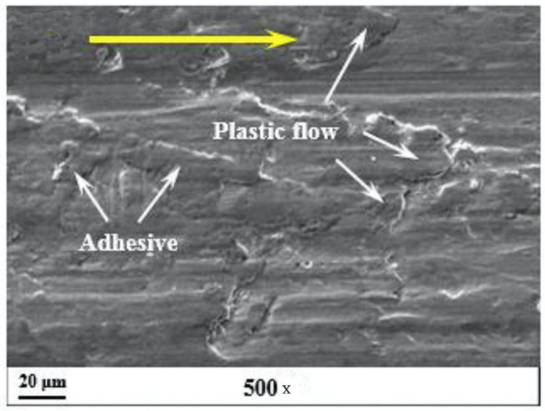

(d)

Figure 4. The worn surface morphology of $\mathrm{ZrO}_{2}$-toughened $\mathrm{Al}_{2} \mathrm{O}_{3}$ particles reinforced highchromium cast iron (HCCI) matrix composite at different loads: (a) $300 \mathrm{~N}$-low magnification; (b) 300 N-high magnification; (c) 900 N-low magnification; and (d) 300 N-high magnification [32]. 
Figure 4 shows some of the wear mechanisms found on the worn surface of $\mathrm{ZrO}_{2}$ toughened $\mathrm{Al}_{2} \mathrm{O}_{3}$ particles reinforced high-chromium cast iron (HCCI) matrix composite with different forms of wear phenomenon pointed.

(b) Molecular deformation

When molecules at the interfaces of the sliding surfaces encounter each other, adhesion of surface atoms of the thin film with the tip of the counter body takes place. 2D materials are known for their low stiffness in the transverse direction [33]. They can easily deform or delaminate depending on the tip-layer adhesion strength. This lateral deformation of 2D layers due to adhesion is known as atomic corrugation. Atomic corrugation leads to molecular deformation and heat generation [34]. Figures 5 and 6 show the molecular dynamics simulation result between friction force $F_{f}$ and contact force $F_{c}$ for suspended graphene and isotropic graphite at nanoscale contact. Simulations were done at different contact tip diameters for Vander Waals adhesion contact/retract and full-range force sweep conditions (experiments), respectively. The analytical values for these simulations are shown as an insert in Figure $5 a, b$. Figures $5 b$ and $6 b$ show the $F_{f}$ vs. $F_{c}$ relation when tip-sample interfacial Vander Waals forces are increased four times. When the interfacial interaction energy was increased, the magnitude of negative contact load also increased substantially. Negative contact load signifies adhesion between the interfacial atoms due to molecular deformation. Energy is required to break this contact interaction, which is released as frictional heat. The presence of dislocations and inclusion can also increase the corrugation energy as energy is lost as heat to overcome or move these defects. Higher the number of dislocation motion, the higher the heat generated due to molecular deformation [35].

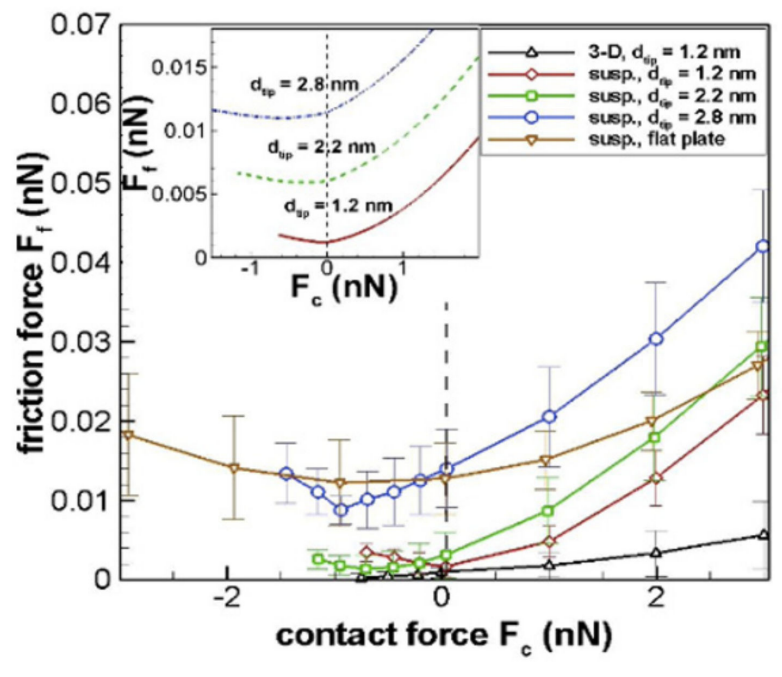

(a)

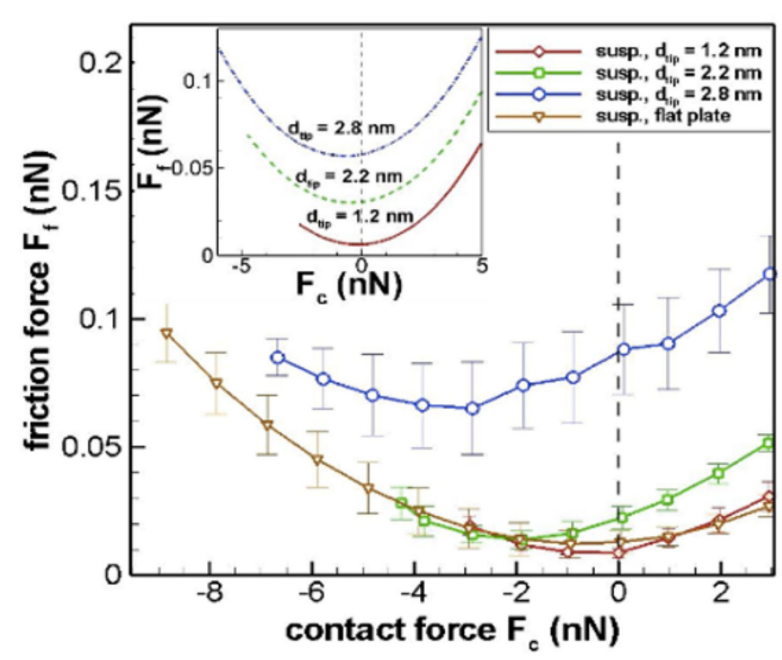

(b)

Figure 5. Atomistic simulation result of frictional force $\left(F_{f}\right)$ versus contact force $\left(F_{c}\right)$ for suspended graphene interlayer adhesion: (a) tip sample empirical interlayer adhesion, and (b) when tip sample interaction Vander Waal's force increased by 4 times that of (a). Inserts show analytical estimates of $F_{f}$ verses $F_{c}$ different spherical tip diameters. (Here, susp indicates suspended graphene whereas 3-D indicates isotropic graphite [34]. 


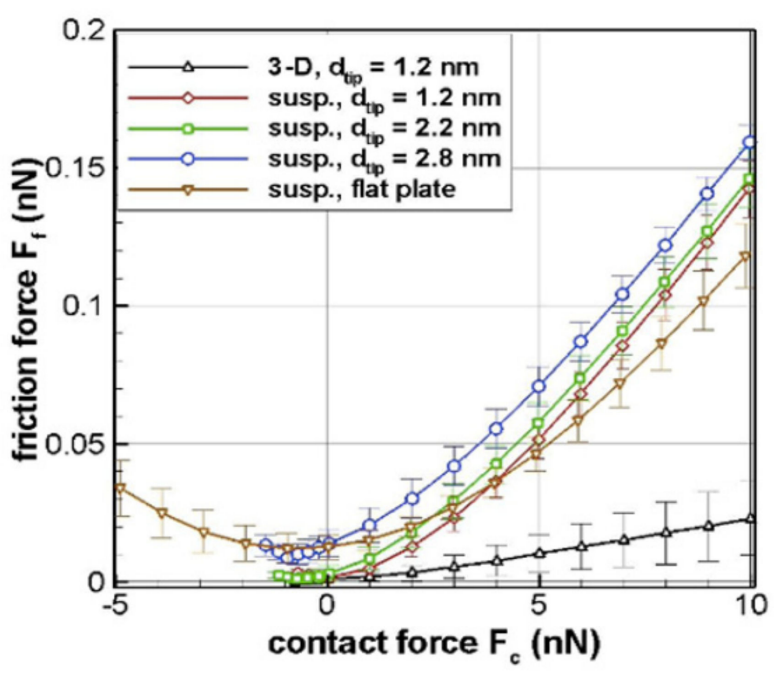

(a)

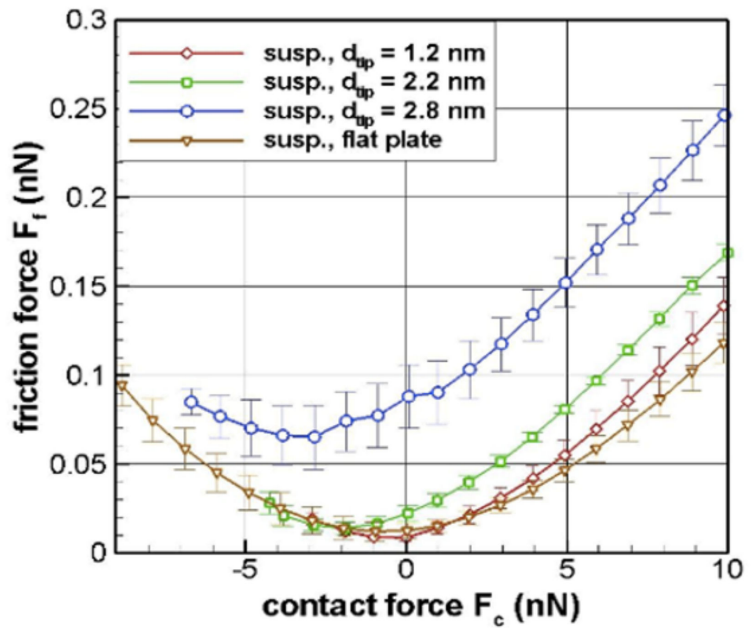

(b)

Figure 6. Atomistic simulation result of frictional force versus full range sweep of contact force for suspended graphene interlayer adhesion: (a) for empirical interlayer adhesion at a constant Van der Waal's force and (b) for empirical interlayer adhesion when Van der Waal's forces are increased by 4 times that of (a). (Here, susp. indicates suspended graphene whereas 3-D indicates isotropic graphite [34].

(c) Thermal effect

At a certain temperature, molecules and atoms gain enough energy to move around and across the interface. The rate of these motions can either increase or decrease depending on the surrounding temperature or heat generated due to frictional interaction. The rate of these fluctuation also depends on the interaction potential between the atoms and molecules. When the interaction potential is high, the overall effect of thermal activation on heat generation decreases [36]. In this case, more heat is required to produce these effects. This is attributed to the thermally actuated hooping mechanism of atoms, which ease sliding. The thermal effect of heat generation depends on the sliding velocity and lateral frequency of the sliding interface $[37,38]$. Figure 7 shows the variation of potential energy with interatomic distance. The higher the depth of the potential well, the more energy is required to overcome the interaction potential, and hence, thermal effect on friction becomes less. In addition, with an increase in depth of the potential well, the melting point of the material increases.

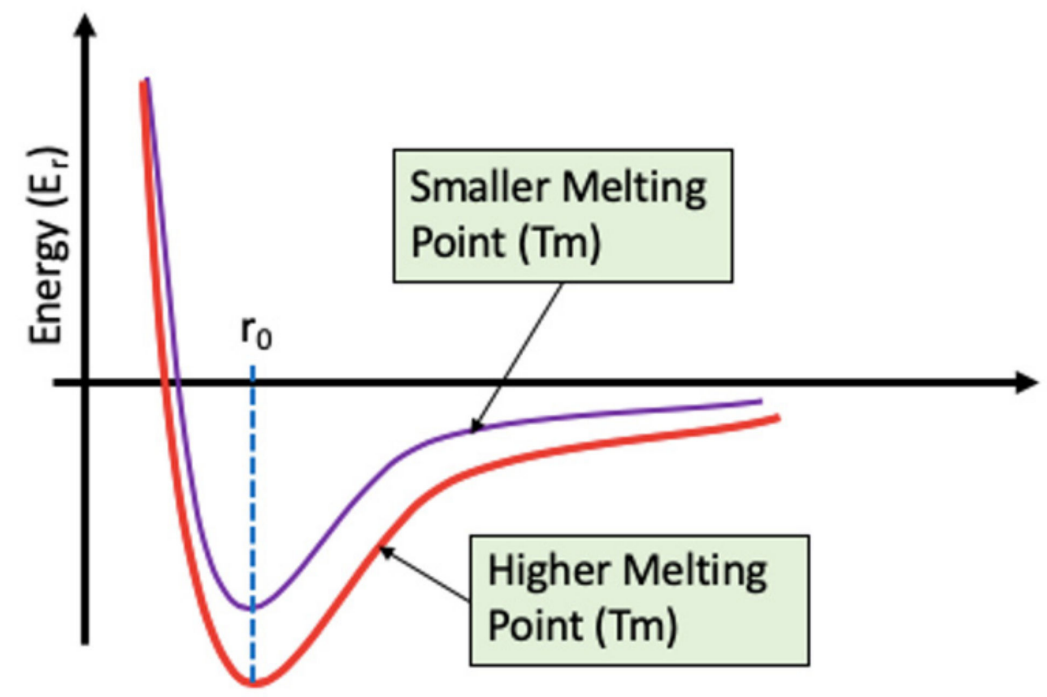

Figure 7. Typical potential energy curve showing the shape of the well with increase in melting point [39]. 
(d) Bonding

One of the most important issues associated with an increase in friction is related to chemical interactions at the asperity contacts. Bonding can occur between the rubbing surfaces or in the presence of environmental reactants. The formation and breakage of these bonds during the relative motion between rubbing surfaces leads to an increase or decrease in friction based on the nature of the bonding energy [40,41].

The wearing process mostly involves breaking of metallic bonds with high bond dissociation energy and thus produces heat since these reactions are exothermic. In addition, surface oxidation and corrosion as a result of environmental reactants are also exothermic and lead to heat generation. The higher the bond dissociation energy, the higher the heat generated. Figure 8 shows the energy difference between the reactants and products for endothermic and exothermic reaction. For exothermic reaction, the energy of the products is less than that of reactants.

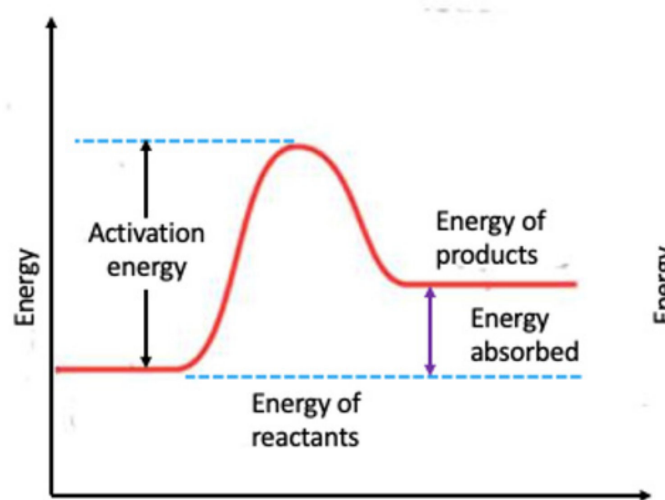

Direction of reaction

a) Endothermic reaction

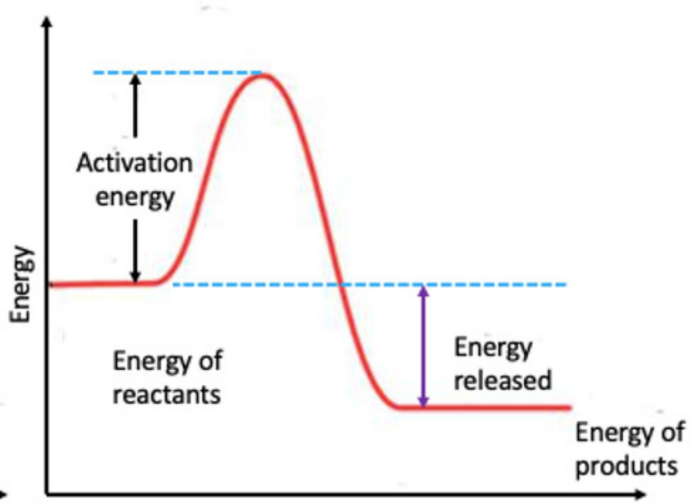

Direction of reaction

b) Exothermic reaction

Figure 8. Schematic showing the energy interaction during endothermic and exothermic reactions: (a) Endothermic reaction- energy of products is higher than energy of reactants and (b) Exothermic reaction- energy of products is less than energy of reactants [42].

The change in their energy is released into the atmosphere as heat. The binding energy of different types of atomic bonds is shown in Table 1. The higher the binding energy, the more heat is released during bond breakage.

Table 1. Binding energy and melting temperature of different bond types [39].

\begin{tabular}{cccc}
\hline Bonding Type & Substance & $\begin{array}{c}\text { Binding Energy } \\
(\text { Kcal/mol) }\end{array}$ & $\begin{array}{c}\text { Melting } \\
\text { Temperature }\left({ }^{\circ} \mathbf{C}\right)\end{array}$ \\
\hline \multirow{3}{*}{ Ionic } & $\mathrm{NaCl}$ & 153 & 801 \\
& $\mathrm{MgO}$ & 239 & 1000 \\
& $\mathrm{Si}$ & 108 & 1410 \\
\hline \multirow{3}{*}{ Covalent } & $\mathrm{C}$ & 170 & $>3550$ \\
& $\mathrm{Hg}$ & 16 & -39 \\
& $\mathrm{Al}$ & 77 & 660 \\
\hline \multirow{2}{*}{ Metallic } & $\mathrm{Fe}$ & 97 & 1538 \\
& $\mathrm{~W}$ & 203 & 3410 \\
\hline \multirow{2}{*}{ Van der Waals } & $\mathrm{Ar}$ & 1.8 & -189 \\
& $\mathrm{Cl} 2$ & 7.4 & -101 \\
\hline
\end{tabular}

(e)Environment

Solid-film lubrication is highly dependent on the environment. The chemical and physical interactions between the film and the surrounding environment greatly affect the tribological performance [43-45]. Table 2 shows the effect of some environmental factors 
such as humidity and temperature on the lubricating properties of some of the widely used solid lubricants.

Table 2. Effect of environmental factors on the lubricating properties of some known solid lubricants.

\begin{tabular}{|c|c|}
\hline Humidity & $\begin{array}{l}\text { - } \mathrm{MoS}_{2} \text { and diamond like carbon (DLC) friction increases with humidity } \\
\text { Graphene, h-BN, and ultra-nanocrystalline diamond (UNCD) friction decrease with humidity due to } \\
\text { saturation of dangling bonds [22] } \\
\text { In dry condition }(0 \% \text { relative humidity, RH) hydrogenated DLC shows super lubricity }(\mathrm{COF}<0.01) \text { due } \\
\text { to shear-induced structural changes [46] }\end{array}$ \\
\hline Nitrogen & $\begin{array}{ll}- & \text { h-BN loses lubricating property } \\
\text { - } & \text { hydrogenated DLC show super lubricity with trace water content (120 ppm) [47] }\end{array}$ \\
\hline Oxygen & $\begin{array}{l}\text { - } \mathrm{h}-\mathrm{BN} \text { loses lubricating property due to oxidation } \\
\text { - } \quad \mathrm{MoS}_{2} \text { is also susceptible to atomic oxygen and decreases the lubricating effect }\end{array}$ \\
\hline Hydrogen & $\begin{array}{l}\text { - Improves the tribological performance of amorphous nonhydrogenated DLC by hydrogen termination } \\
\text { - } \quad \text { For hydrogenated DLC, the presence of small amount of water (120 ppm) increases friction [48] }\end{array}$ \\
\hline Temperature & $\begin{array}{l}\text { - For } \mathrm{MoS}_{2} \mathrm{COF} \text { decreases with the increase in temperature due to desorption of water up to } 300{ }^{\circ} \mathrm{C} \text {. At } \\
400{ }^{\circ} \mathrm{C} \text {, oxidation of } \mathrm{MoS}_{2} \text { causes deterioration of tribological properties } \\
\mathrm{WS}_{2} \text { and } \mathrm{WSe}_{2} \text { can resist oxidation up to } 700^{\circ} \mathrm{C}\end{array}$ \\
\hline Vacuum & $\begin{array}{l}\text { - } \quad \text { h-BN loses lubricating property } \\
\text { - } \quad \text { DLC and diamond shows high friction due to desorption of hydrogen [49] } \\
\text { - } \quad \text { water desorption deteriorates the lubricating property of graphite and graphene }\end{array}$ \\
\hline
\end{tabular}

\section{Graphite and Graphene}

Graphite is known for its lubricating property from ancient times based on its outstanding qualities as solid lubricant in humid environment. This is due to the weakening of the interlayer Van der Waals forces or the dangling bonds because of the saturation by $\mathrm{H}+$ and $\mathrm{OH}$ - ions from humidity [50-52]. Therefore, the graphite has been used as an additive in various solid lubricants to improve their tribological performance in a humid environment [53]. Presently most investigation involving graphite as a solid-lubricant focus on improving the wear and friction of different grades of steels for various industrial applications [54-56].

Since the discovery of graphene, its electronic properties have gained a lot of attention, and it has been deemed as a promising material that can revolutionize the electronic industry, prompting a substantial number of investigations on understanding its behavior at nano-, micro-, meso-, and macro-scales [57]. Consequently, the electronic, mechanical, and tribological properties of graphene are more established theoretically and experimentally than other novel 2D materials. The tribological behavior of different 2D materials is also affected by their structure, reactivity of different functional groups, chemical affinity to environmental species, and thickness of deposited layers [58-60]. Extensive studies on atomistic and molecular scale friction, the effect of external factors, and the influence of addition of atoms or molecules on the electronic and tribological properties of graphene are crucial to an in-depth and systematic understanding of the physics of macroscopic friction [61-63]. These studies indicate a clear difference in frictional behavior at macroscale compared with microscale and atomic level. Understanding these microscopic tribological effects is important to achieve super lubricity for practical application over wide ranges of atmospheric and mechanical conditions $[64,65]$.

Investigations on interlayer and intralayer sliding friction are important for understanding the modes of heat generation, dissipation, and their control to achieve super lubricity at macroscale [66,67]. Experimental studies conducted by Kamiya et al. [68] and Dienwiebel et al. [69] on the interlayer sliding of graphene/graphite concluded that the nanoscale friction is highly anisotropic and dependent on the relative angle (rotation angle) of sliding layers as shown in Figure 9. At $0^{\circ}$ and $60^{\circ}$ angles of rotation, the nanoscale 
friction and interaction energy indicated by negative sign convention signifying attraction are higher than other angles, and the sliding occurring at these angles is termed as commensurate sliding. If the relative sliding angle is not equal to the commensurate stage, the frictional force is reduced considerably; this phenomenon is known as incommensurate sliding. This incommensurate sliding of graphene and its associated high flexibility in the out-of-plane direction even with thermal excitation [70] has been exploited to achieve macroscopic super lubricity with graphene-coated nanospheres to promote hetero structural interface sliding as shown in Figure 10a.
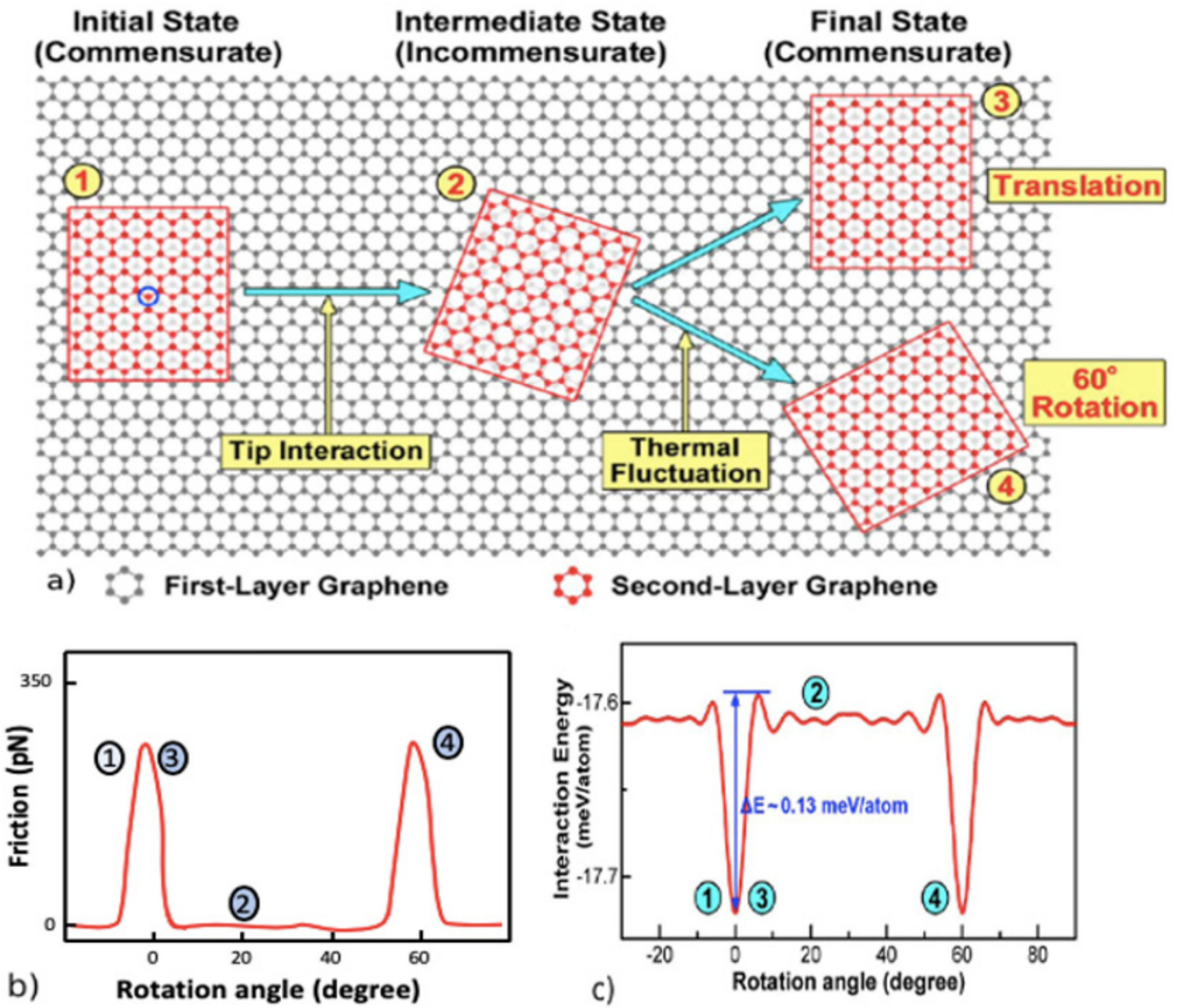

Figure 9. (a) Schematic of commensurate and incommensurate sliding of one graphene layer over another [71]; (b) variation of nanoscale friction with respect to the change in relative angle of rotation [69]; and (c) interaction energy as a function of rotation angle. Negative interaction energy signifies attractive forces and increase in friction increases [71]. 


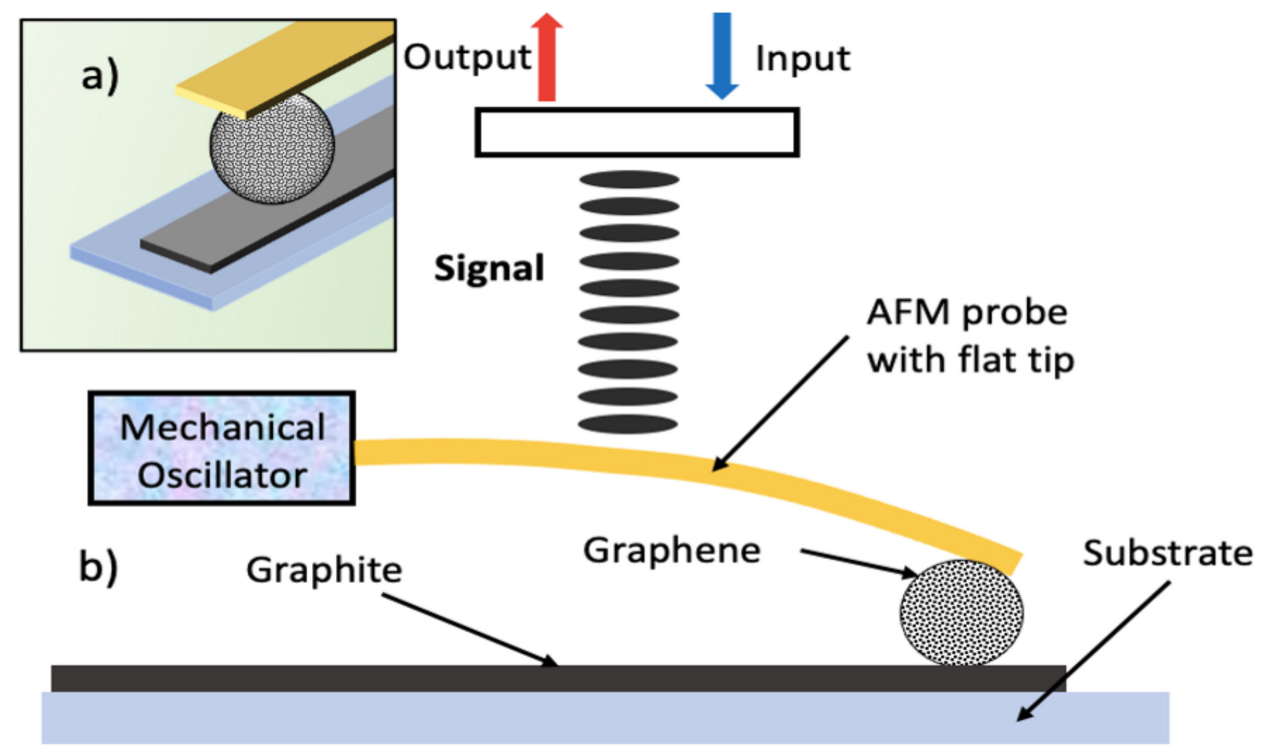

Figure 10. Incommensurate heterostructure interface sliding of multilayer graphene-coated microsphere (GMS) on graphene substrate using tipless mode of atomic force microscope (AFM) (a) isometric view and (b) schematic of atomic force microscopy of GMS sliding on graphene layers (After [72]).

The friction on heterostructure interfaces was studied by sliding multilayer graphenecoated microsphere (GMS) on different 2D materials using an atomic force microscope (AFM) by Liu et al. [72]. They reported formation of a multiasperity contact with substrates by coated microsphere, resulting in incommensurate interfaces and suggests that superlubric sliding can be achieved for heterostructure multiasperity interfaces. Berman et al. [73] reported to achieve macroscopic super lubricity between graphene and diamondlike carbon due to the formation of nanorolls by a spontaneous wrapping of low stiffness graphene layers during sliding. This produced an incommensurate multiasperity sliding (Figure 10), which was super lubric with a friction coefficient of $\sim 0.004$.

Sliding friction on the surface of the graphene is highly dependent on the thickness or the number of atomic layers. With an increase in the number of layers, the friction force decreases and is independent of normal force, sliding velocity, and the tip material. Lee et al. [74] studied the effect of number of graphene layers on friction force using mica substrate, which is highly adhesive to graphene. They reported absence of thicknessdependent frictional effect and attributed it to the decrease in friction with increased graphene layers to the low stiffness of the graphene layers. When graphene interacts with AFM tip in contact mode, graphene adheres to the tip, thus producing a puckering effect and wrinkling, which further increases the friction. The high adhesiveness of the substrate material inhibits the formation of wrinkles, and friction becomes independent of the number of layers, which was later confirmed by various research works that reportedly used atomically thin films subjected to different atmospheric conditions [75-77].

Significant research has been conducted on the effect of topology defects [78-81] and the presence of functionalization groups $[82,83]$ on heat generated due to friction. Atomic steps and step edges results in high friction and heat dissipation due to SchwoebelEhrlich barrier [84,85]. Local out-of-plane deformation of the graphene layers increases the number of step edges and lead to additional heat generation [86,87]. The presence of functionalization groups such as hydrogen, fluorine, and oxygen is known to increase the frictional heat, which is assumed to be arisen from the atomic roughening of graphene due to its $\mathrm{sp}^{3}$-bonding and increase in atomic corrugation [88] and an increase in out-of-plane stiffness. Ko et al., further showed that hydrogenated, fluorinated, and oxidized graphene exhibited two, six, and seven times increase in friction compared with pristine graphene, respectively [58]. 


\section{Transition Metal Sulfides and Di-Selenides}

Transition metal sulfides and selenides such as $\mathrm{MoS}_{2}, \mathrm{WS}_{2}, \mathrm{MoSe}_{2}$, and $\mathrm{WSe}_{2}$ are an important class of 2D lubricating materials, especially in space exploration design [89]. These materials are known for their very low friction coefficient in dry and vacuum conditions over a wide temperature range in addition to their stability in radiative environments [90-92]. Among these materials, $\mathrm{MoS}_{2}$ is extensively investigated and used for astronomical applications. The tribological performance of other transition metal disulfides and di-selenides is comparable to that of $\mathrm{MoS}_{2}$ due to their similarity in structure and are also used as a solid-film lubricant [93]. Tungsten-based disulfide and di-selenide are used for high-temperature applications due to their thermal stability and oxidation resistance [94,95]. $\mathrm{MoS}_{2}$ is reported to lose its lubricating property around $300{ }^{\circ} \mathrm{C}$ due to oxidation, whereas tungsten compounds can maintain lubricity up to $600{ }^{\circ} \mathrm{C}[96,97]$. The lubricious property of these solid films is highly dependent on the microstructure and dopant concentration. The microstructure and their adhesiveness to the substrate are also dependent on the deposition method and deposition parameters such as coating power, time, and the temperature. High-quality films of transition metal disulfides and di-selenides with improved tribological performance produced by using sputter deposition method have also been extensively reported [98]. Various sputtering processes such as co-deposition, multiplayer, and multiphase deposition are used frequently to produce high-quality transition metal lubricious films that can withstand high loads and possess higher wear resistance [99-101].

The solid-lubricating properties of these transition materials are known to deteriorate due to the adsorption of atmospheric humidity, the presence of oxygen, and at higher temperatures $[43,102,103]$. Studies have reported an increase in friction at room temperature due to adsorption of water, which notably does not promote oxidation of $\mathrm{MoS}_{2}$. This increase in friction as a result of adsorbed water also restricts the growth of surface tribo-films on the counter surface at room temperature [104]. Curry et al., conducted experiments on highly oriented $\mathrm{N}_{2}$-sprayed $\mathrm{MoS}_{2}$ and sputtered amorphous $\mathrm{MoS}_{2}$ films [105]. The performance of these highly oriented crystal with the basal plane perpendicular to the c-axis showed enhanced performance under humidity and at high temperatures in the absence of molecular oxygen. An increase in temperature and in the presence of oxygen, the surface oxidation of $\mathrm{MoS}_{2}$ films leads to an increase in friction coefficient. These oxide films are usually a few nanometers thick and wear off easily, and therefore, exposing the underlying unoxidized $\mathrm{MoS}_{2}$ films improves overall tribological performance with time. Thus, it was concluded that adsorption of water molecules reduces the tribological performance of $\mathrm{MoS}_{2}$ films compared with the oxidation of a solid film [106,107]. Prasad et al., investigated the quality of the $\mathrm{WS}_{2}$ transfer film and noted a deterioration of friction coefficient in the presence $50-60 \%$ relative humidity in the air, a trend like that of $\mathrm{MoS}_{2}$ [108].

Another characteristic feature of $\mathrm{MoS}_{2}$ coatings is the establishment of low friction during the running-in which is enhanced by high loads and can be supported by frictioninduced surface crystallization [109]. The formation of a basal-oriented transfer film on the counter-body sliding against a randomly oriented $\mathrm{MoS}_{2}$ film has also been reported [110]. Although the reorientation process results in a lower and a stable coefficient of friction, it is shown to significantly decrease the wear resistance of the coating under higher humidity. Tungsten disulfides and selenide show higher thermal stability compared with its molybdenum counterparts. Hence, tungsten-based compounds are known for its lubricating properties at a higher temperature.

Many investigations have been conducted to improve the tribological performance of these films under humidity and for high-temperature applications. Films grown parallel to the substrate (001) are preferred for solid lubrication because their edge sites (step edges), which are more reactive to oxidation and corrosion are masked from the surface. The quality of the synthesized films is also dependent on deposition parameters such as pressure, temperature, and the substrate among other factors. It has been found that sub-stoichiometric films with sulfur and selenide deficiency decreases the probability of 
re-sputtering, thereby improving the tribological performance [111,112]. An augmented metallic interface between the film and the substrate improves the adhesive property of the film $[113,114]$. The addition of different materials was also shown to alter the grain structure, orientation, and the performance of the solid film [115]. Doping or co-deposition and using layered films generated through multilayer deposition of various materials are frequently used to improve the resistance of the films under varying humidity and temperature conditions [116].

Titanium is a widely used co-dopant in $\mathrm{MoS}_{2}$-sputtered films [117]. Rigato et al. [118] reported that the doping of Ti within the layered structure of $\mathrm{MoS}_{2}$ increases the distance between $\mathrm{MoS}_{2}$ layers and reduces the interlayer friction. Renevier et al. [119] reported that MoS (Ti) produced by close-field unbalanced magnetron sputtering was found to be harder by factors of 1000-2000 than hardness of $\mathrm{MoS}_{2}$ ( $\left.\sim 400 \mathrm{HV}\right)$ and were much more wear-resistant by a factor of $\sim 100$. They were also identified to be lesser sensitive than the atmospheric water vapor, showing an improvement by a factor of 2800 compared with $\mathrm{MoS}_{2}$. Quin et al. [120] examined hybrid high-power impulse magnetron sputtered (HIPIMS) MoS (Ti) films and demonstrated that the crystallization degree of the $\mathrm{MoS}_{2}$ (Ti) composite coatings decreases with an increase in Ti dopant concentration. This is due to the reactivity of Ti with $\mathrm{O}$ that results in the formation of titanium oxides on the surface, inhibiting the oxidation of $\mathrm{MoS}_{2}$ and achievement of the lowest coefficient of friction (COF) at 0.04 and at the wear rate of $10^{-7} \mathrm{~mm}^{3} \mathrm{~N}^{-1} \mathrm{~m}^{-1}$ at the optimum Ti content of $13.5 \%$ (Figure 11).

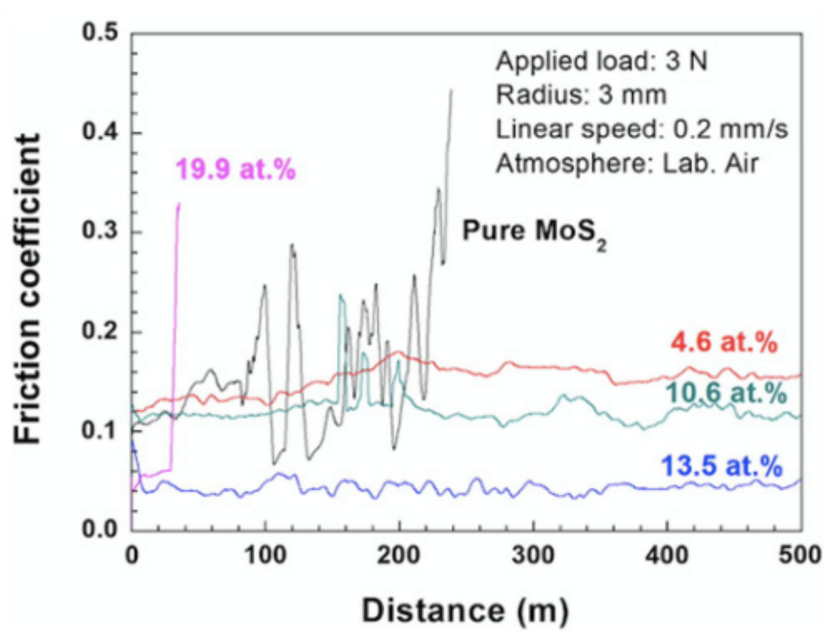

(a)

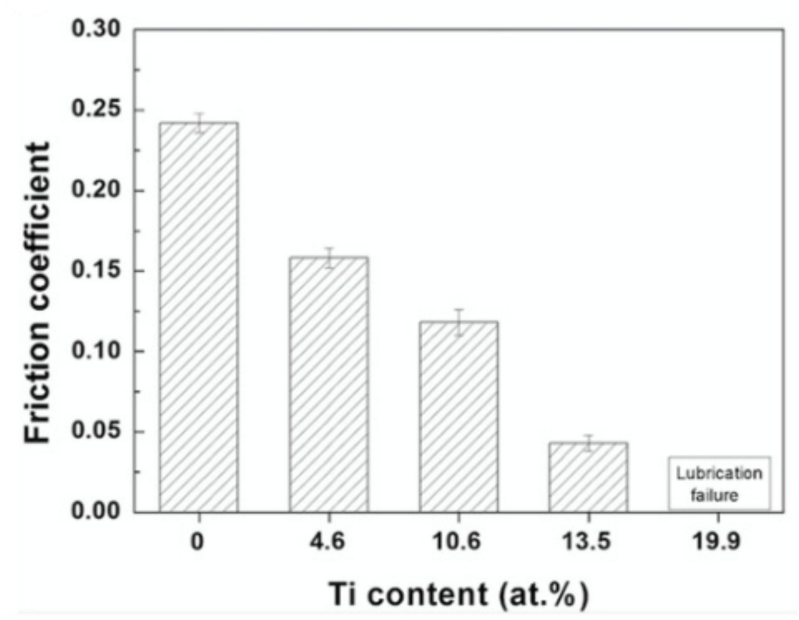

(b)

Figure 11. (a) Sliding friction curve and (b) mean coefficient of friction as a function of Ti content for sputter-deposited $\mathrm{Ti} / \mathrm{MoS}_{2}$ films [120].

Ding et al., showed that an increase in $\mathrm{Cr}$ doping on $\mathrm{MoS}_{2}$ led to a substantial decrease in the wear rate and friction with humidity up to 9.6 at \% of $\mathrm{Cr}$ as indicated in Figure 12. Also, addition of metals such as $\mathrm{Au}$ [121], Cr [122], Ni [123,124], Cu [125,126], Zr [127], and metal compounds such as $\mathrm{Sb}_{2} \mathrm{O}_{3}, \mathrm{WSe}_{2}$ have improved the performance under humid air and vacuum compared with sputter-deposited pure $\mathrm{MoS}_{2}$. Doping of $\mathrm{WSe}_{2}$ in $\mathrm{MoS}_{2}$ films leads to the substitution of sulfur atoms by selenide, which creates a curvature in the linear $\mathrm{MoS}_{2}$ structure by increasing the interlayer spacing, as shown schematically in Figure 13 [128]. Few metal dopants facilitate the parallel orientation of basal plane with the substrate in the sliding direction, protect the edge sites from oxidation and further reacts with oxygen to form lubricious metal oxides that improve their performance in humid atmospheric conditions $[119,129,130]$. The interstitial and substitutional defects increase the interlayer spacing and aids in easy cleavage, thereby reducing interlayer friction. 


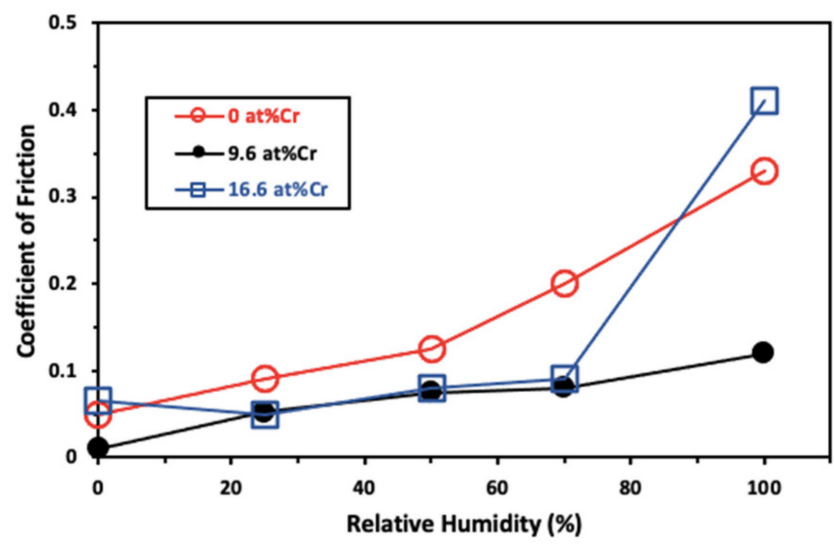

(a)

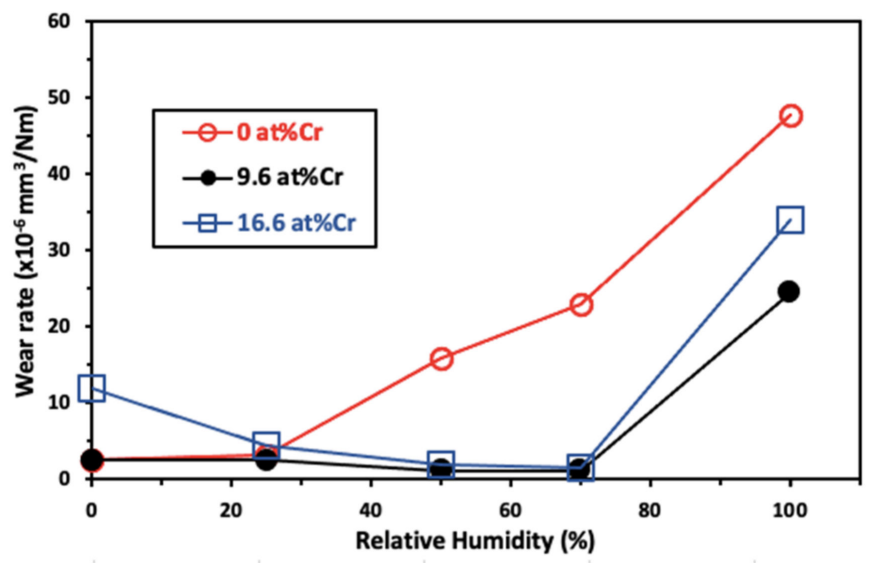

(b)

Figure 12. Friction coefficient and wear rate on sputter deposited $\mathrm{MoS}_{2} / \mathrm{Cr}$ composite film as a function of $\mathrm{Cr}$ content at different humidity levels: (a) variation friction coefficient with relative humidity and (b) variation of wear rate with relative humidity [122].

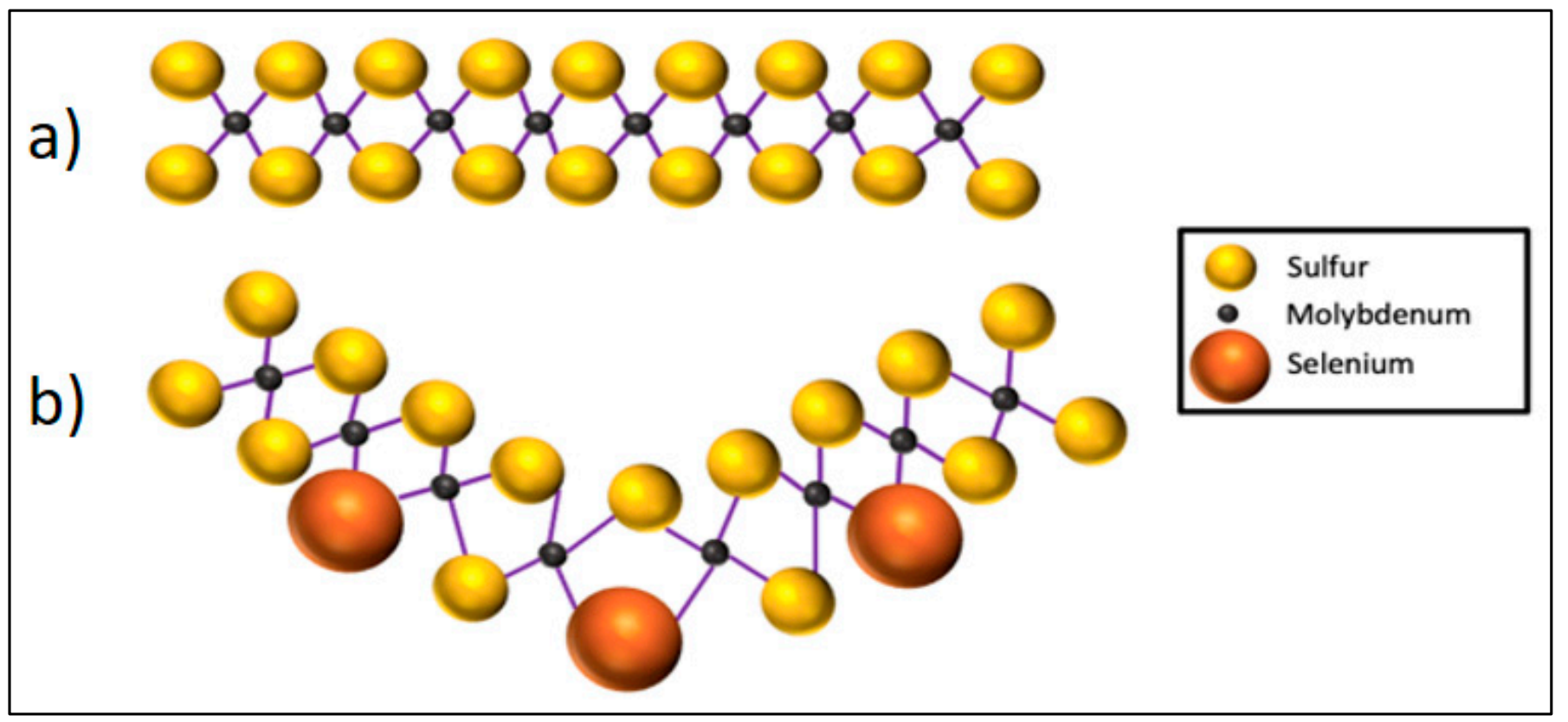

Figure 13. (a) $\mathrm{MoS}_{2}$ layer and (b) substitution of the sulfur atom by selenide leads to a curved structure (after [128]). This increases interlayer distance and reduces friction.

Doped amorphous carbon and DLC (diamond-like carbon) have also been investigated for improvement in the tribological performance of transition metal dichalcogenides under humid conditions. Notably, the addition of smaller amounts of $\mathrm{MoS}_{2}$ in carbon-based compounds facilitate the formation of graphite-like structure [131]. $\mathrm{MoS}_{2} /$ carbon-doped composite has been highly investigated to improve the strength, wear resistance, and tribological performance of transition metal dichalcogenides in humid environments [131]. Studies have shown that the addition of graphite, r-graphene oxide, DNC, and amorphous carbon to transition metal dichalcogenides improves the tribological performance in humid environments [132].

Multilayer films deposited by sputtering are proven to have superior lubricating properties than the pure solid-film lubricants. The improved performance of these films is due to their increased hardness arising from their distinct superlattice structure of the resultant multilayer films [133]. Mikhailov et al. [134] investigated the performance of multi- 
films of $\mathrm{MoS}_{2}$ using $\mathrm{Au}, \mathrm{Ni}, \mathrm{Pb}$, or PbO films as the ancillary layer that exhibited higher performance at $50 \% \mathrm{RH}$, and it was hypothesized that the improved performance is because the addition of the elements helps in the basal orientation of $\mathrm{MoS}_{2}$ and hence improves the performance. In another study conducted by $\mathrm{Li}$ et al. [135] involving $\mathrm{Pb}-\mathrm{Ti} / \mathrm{MoS}_{2}$ nanoscale multilayer films produced by sputtering, it was found that the films advanced from a multilayer structure to a composite structure as the bilayer period decreased from 25 to $6 \mathrm{~nm}$ due to diffusion of atoms within the bilayer. Hence, there should be a minimum bilayer period thickness to make sure the films formed are multilayer and not composite coating. The nanoscale multilayer film with a bilayer period of $20 \mathrm{~nm}$ exhibited superior mechanical and tribological properties than pure $\mathrm{MoS}_{2}$, implying that a certain minimum critical bilayer thickness is crucial to produce multilayer films.

In multilayer deposition, a metallic layer of metals such as $\mathrm{Cr}$ and $\mathrm{Ti}$ is deposited as the first layer to improve the adhesion of multilayer solid films on to substrate [136]. Hilton et al., formed sputtered $\mathrm{Ni}-\mathrm{MoS}_{2}$ and $\mathrm{Au}-(20 \%) \mathrm{Pd}-\mathrm{MoS}_{2}$ multilayer films with appropriate layer spacing and thickness to induce excellent endurance under dry nitrogen and air environments [129]. The thickness of the interlayer distance determines the hardness, microstructure, and superlayer structure, which affects the tribological performance. Many studies report using multilayer and multiphase deposition techniques to find optimum interlayer spacing and composition to identify the best lubricious solid film to address the current needs [99,137-139]. Figure 14 summarizes research works conducted on $\mathrm{MoS}_{2}$ and $\mathrm{WS}_{2}$ co-deposited and multilayer films. The range of friction coefficient and wear rate for carbon-based films and sputter-deposited transition metal sulfides and di-selenides films are shown in Figure 15.

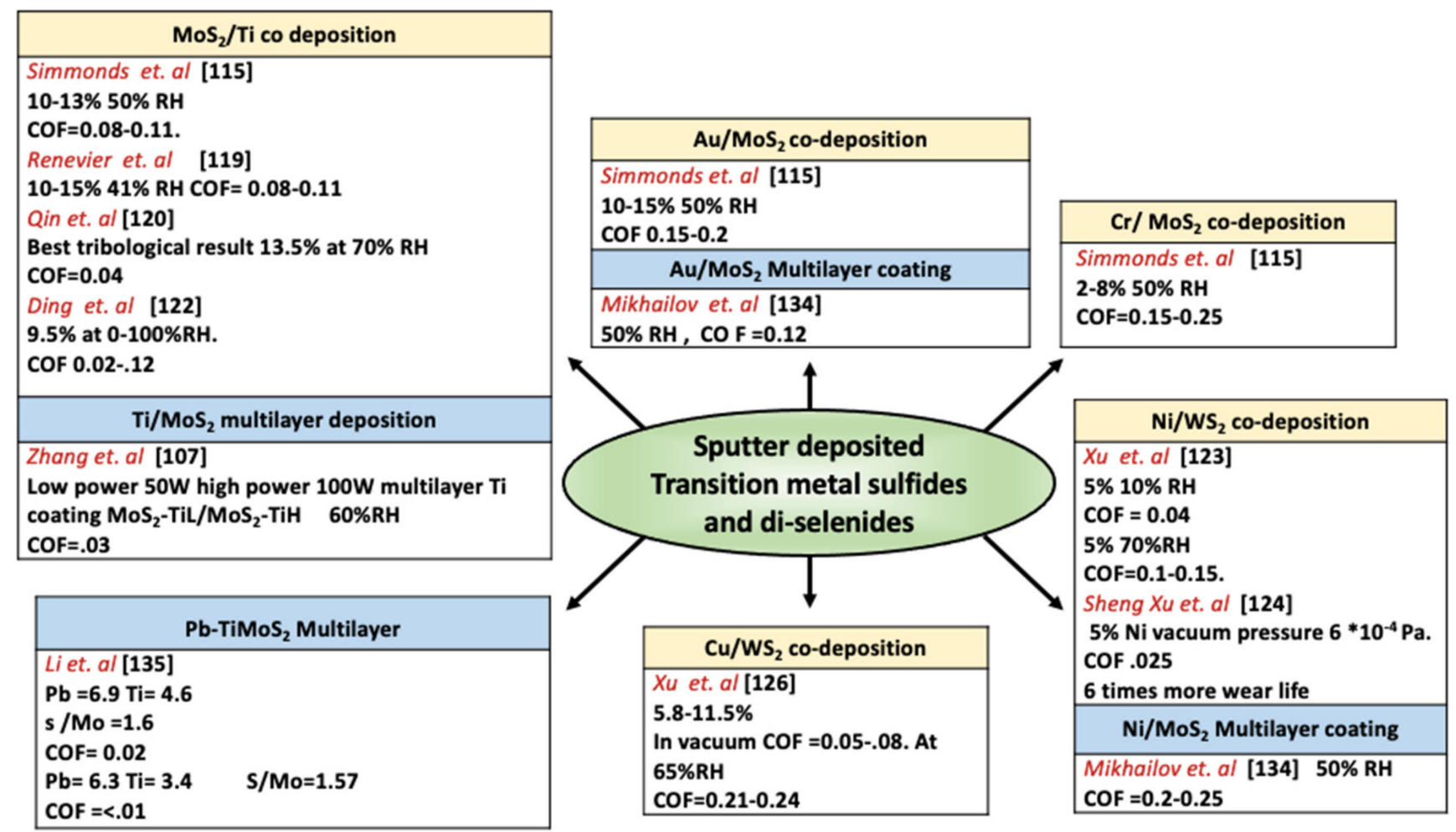

Figure 14. Some publications on co-deposited and multilayer $\mathrm{MoS}_{2}$ and $\mathrm{WS}_{2}$ films. $[115,119,120,122-124,126,134,135]$. 


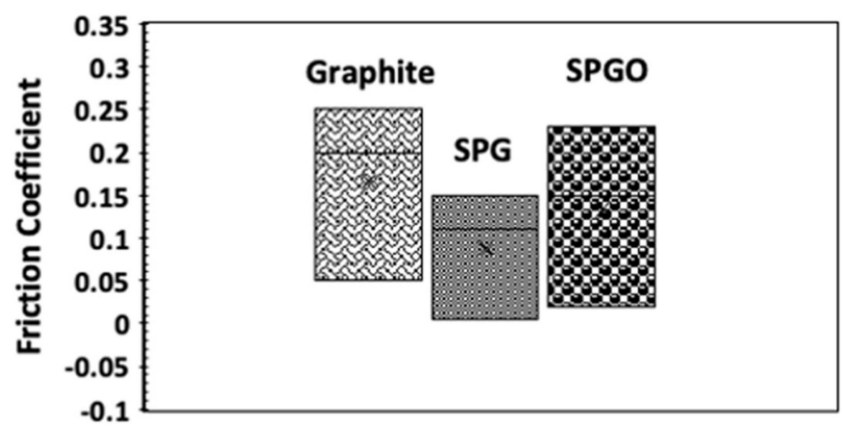

(a)

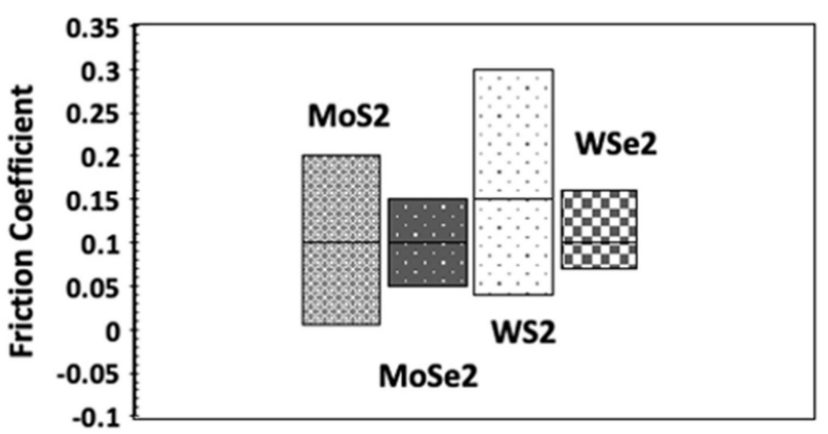

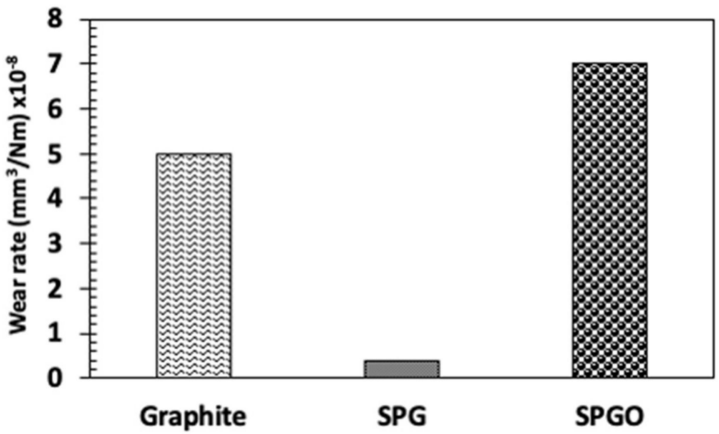

(b)

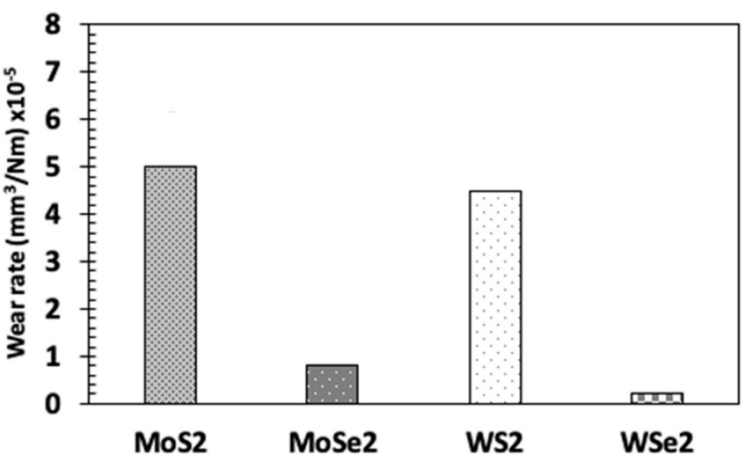

Figure 15. The range of friction coefficient and wear rate for carbon-based films and sputter-deposited transition metal sulfides and di-selenides films: (a) Friction coefficient range for carbon-based films; (b) Wear rate range for carbon-based film; (c) Friction coefficient range for sputter-deposited transition metal sulfides and di-selenides films; and (d) Wear rate range for sputter-deposited transition metal sulfides and di-selenides films [102,140-144].

Boron compounds are used extensively in a wide range of tribological applications as an environment-friendly friction modifier and antiwear additive. Both organic and inorganic boron compounds are used as a solid, liquid lubricant [145-147] and as a lubricant additive in organic and inorganic compounds [12,148,149]. Boron-based lubricants are mostly explored for industrial application as a solid or ionic liquid lubricant. Among all boron compounds, hexagonal boron nitride and boric acid are investigated as a solid lubricant.

Hexagonal boron nitrides (h-BN) also known as white graphite have been shown to have inferior lubricating abilities compared with graphite and $\mathrm{MoS}_{2}$ because of the existence of stronger interlayer Van der Waals forces that restrict the cleavage [150-152]. The h-BN has higher temperature stability compared with other solid lubricants and functions well in a humid environment. In contrast to other solid lubricants, h-BN can withstand higher sintering temperature during the powder metallurgical manufacturing processes by virtue of their higher phase-transformation temperature [152,153]. Presently most industrial applications of h-BN focus on improving the tribological performance of different grades of steel for industrial applications [152,154].

Mahathanabodee et al. [152] studied hexagonal boron nitride (h-BN)-embedded $316 \mathrm{~L}$ stainless steel (SS316L/h-BN) composites prepared via high-temperature powder metallurgy process and established that increasing h-BN content in the composition leads to a decrease in the hardness, which can be improved by increasing the sintering temperature during the manufacturing process. The best tribological results were obtained for $20 \mathrm{vol} \%$ of h-BN at a sintering temperature of $1200{ }^{\circ} \mathrm{C}$, which is slightly higher than its melting point of $1250^{\circ} \mathrm{C}$. Avril et al. [155] examined $\alpha-\mathrm{Fe}(\mathrm{Cr})-\mathrm{h}-\mathrm{BN}$ and $\alpha-\mathrm{Fe}(\mathrm{Cr})-\mathrm{Fe} 2 \mathrm{~B}-\mathrm{FeB}$ films generated on $\mathrm{X} 30 \mathrm{Cr} 13$ stainless steel by a laser-melting process that showed an improvement in the tribological properties with the addition of h-BN [156,157]. Miyake et al. [158] investigated the effects of multilayers $(\mathrm{C} / \mathrm{BN}) \mathrm{n}$ films with thickness in nanometric range 
that were produced by RF sputtering and found the layer thickness of $4 \mathrm{~nm}$ showed the lowest friction coefficient of 0.1 at $25^{\circ} \mathrm{C}$.

Zishan et al. [159] explored the temperature stability of $\mathrm{SiC}$ and (SiC/h-BN) composite coatings prepared by the pack cementation process on carbon/carbon $(\mathrm{C} / \mathrm{C})$ substrate. Their findings supported the addition of h-BN that resulted in stabilization of the friction coefficient of $\mathrm{SiC}$ coating at room temperature. At $600{ }^{\circ} \mathrm{C}$, the tribological behaviors of both the coatings showed a higher friction coefficient of 0.75 ; however, at $800^{\circ} \mathrm{C}$, the $\mathrm{SiC}$ coating underwent severe wear and $\mathrm{SiC} / \mathrm{h}-\mathrm{BN}$ composite coating exhibited a lower friction coefficient and wear rate compared with $\mathrm{SiC}$ coating. Tyagi et al. [160] also reported a lower friction coefficient for a sintered coating containing h-BN compared with the base matrix and an improvement in lubricating effects at high loads and speeds [161].

Boric acid has also been explored as potential solid-lubricating borate due to its graphene like structure as shown in Figure 16. Unlike other solid lubricants, boric acid dehydrates at $170{ }^{\circ} \mathrm{C}$ forming oxides that lack the lubricating property. In addition, during sliding at high contact pressure, boric acid solid films can be forced out of the sliding contact area and need to be replenished continuously [162,163]. Due to these issues, boric acid is mostly used in multifunctional systems consisting of solid and ionic liquid lubricants that allows for continuous replenishment of solid-lubricant boric acid crystals [123,164].

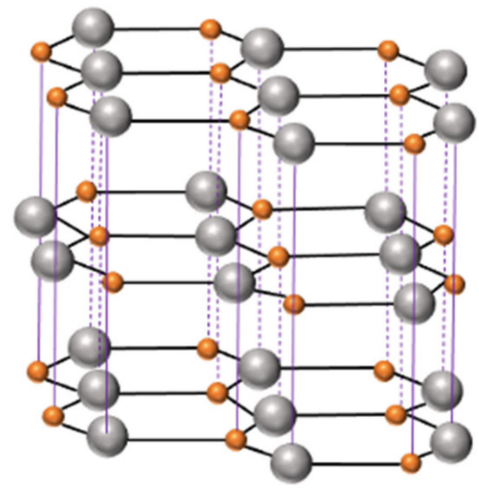

(a)
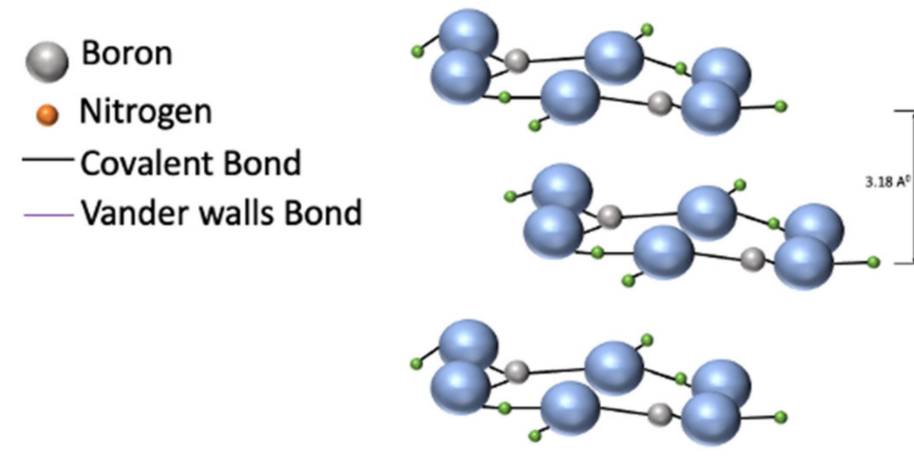

(b)

Figure 16. Structure of h-BN and boric acid: (a) hexagonal boron nitride and (b) boric acid [165].

\section{Phosphorus with Layered Structures (Black Phosphorous)}

Black phosphorous (BP) is the most thermodynamically stable and nontoxic of all the amorphous forms of phosphorous at room temperature [166]. In recent years, it has gained prominence as a lubricant additive in polymer composites especially with polytetrafluoroethylene (PTFE) as the composite matrix [167]. The addition of BP facilitates the formation of a tribo-film consisting of phosphorus oxide and phosphoric acid over the time that leads to a decrease in friction coefficient and wear as the rubbing progresses [168].

Lv et al. [169] conducted tribological investigations on polyether ether ketone (PEEK)/ PTFE and carbon fiber (CF)/PTFE composites with 5\% BP nanosheets. The results indicate a dramatic decrease in the coefficient of friction (COFs) and wear rate of both the PEEK/PTFE and CF/PTFE composites in the presence of BP nanosheets. A minimum COF of 0.04 has been reported for both composites with the inclusion of BP. The wear rate of the PTFE/PEEK composite has been observed to decrease with an increase in PEEK concentration, while the wear increased with increasing CF content in CF/PTFE composites. Peng et al. [170] recognized enhanced tribological performance for $0.5 \mathrm{wt} . \% \mathrm{BP} / \mathrm{PTFE}$ compared with $0.5 \mathrm{wt} . \%$ BMG (ball-milled graphite)/PTFE. Table 3 enlists the thermal stability and temperature range of the applications of some solid lubricants. 
Table 3. Thermal stability and temperature range of application of some solid lubricants' $[165,168,171]$.

\begin{tabular}{cccc}
\hline Material & $\begin{array}{c}\text { Temperature } \\
\text { Range }\left({ }^{\circ} \mathbf{C}\right)\end{array}$ & $\begin{array}{c}\text { Temperature of Thermal } \\
\text { Stability }\left({ }^{\circ} \mathbf{C}\right)\end{array}$ & Friction Coefficient \\
\hline MoS $_{2}$ & $-184-400$ & 350 & $0.05-0.25$ \\
SS $_{2}$ & $-184-454$ & 425 & $0.05-0.25$ \\
Graphite & $-184-650$ & 500 & $0.1-0.3$ \\
h-BN & $-184-538$ & 700 & $0.1-0.2$ \\
Boric Acid & $20-80$ & 170 & $0.05-0.07$ \\
Black Phosphorous & & & $0.2-0.33$ \\
\hline
\end{tabular}

\section{Ceramics in Tribology Research}

Ceramic materials with tetragonal and wurtzite structures have been used recently as a solid lubricant for high-temperature applications. Unlike traditional solid lubricants with 2D structure, these materials have stronger intralayer and interlayer covalent bonds. The intralayer covalent bonds is responsible for the brittleness and hardness of the ceramics, and as a result of their brittle nature, the lubricating property of ceramic materials is known to depend heavily on their microstructure under varying temperatures [172-175]. In the case of ceramic materials, the wear and failure happen due to crack initiation and propagation. Karch et al. [176] successfully demonstrated the achievement of ductile fracture of $\mathrm{TiO}_{2}$ ceramics at low temperature for $\mathrm{TiO}_{2}$ ceramic by controlling the stoichiometry, grain size, and crystal orientation both experimentally and analytically. With the advancement in thin-film coating technologies that offer precise control of these deposition process parameters, ceramics can emerge an alternative for high-temperature and corrosive environmental applications.

It has also been shown that the sub-stoichiometric oxide coatings with oxygen vacancies can lead to the development of new crystallographic shear systems due to diffusion creep; consequently, the shear strength and friction coefficient can be controlled by controlling the stoichiometry [177]. The grain size of the oxide films further aids in reducing friction. For instance, the reduced friction of the nanocrystalline $\mathrm{ZnO}$ films is attributed to their sub-micrometer-scale spherical nature that enables a shift in their contact configuration from sliding to rolling. However, these sub-micrometer-sized films possess poor antiwear properties due to their low hardness, which can be improved by inclusion of other elements in films such as nitrogen and carbon. These particles have been shown to squeeze into the grooves on the rubbing surfaces to reduce wear. Nitrogen in particular has been extensively used for reducing the grain size of $\mathrm{ZnO}$. For most oxides, epitaxial growth along the (0001) plane generates the lowest friction coefficient as it has the lowest energy of all the possible crystallographic orientations, which is also known to reduce friction $[178,179]$. The addition of noble metals such as silver and gold also causes these metals to precipitate along the grain boundary thus strengthening the grain boundaries. This reduces diffusion and dislocation along the grain boundary, improves the hardness, and reduces friction $[180,181]$.

\section{Metals, Ceramic, and Polymer-Based Matrix Composites}

Recently, there has been a significant number of investigations using new and advanced manufacturing methods such as powder metallurgy and 3D printing, centered on understanding and improving the tribological performance of solid lubricants. Improving the wear life of solid lubricants has been one of the key challenges in the field of tribology for their reliable industrial and engineering applications. These advanced manufacturing processes help in controlling the microstructure and lubricant concentration with greater precision. Another recent trend in solid-lubrication research is the focus on the manufacturing and characterization of composites comprising of solid lubricants to reduce friction that has been dispersed in a hard matrix to lengthen the wear life [137].

As discussed previously, metal, ceramic, and polymer matrix composites are widely explored as solid lubricants. Currently adopted matrix materials typically consist of met- 
als such as copper [182], steel, and aluminum [183]; ceramics like aluminum oxide and silicon carbide, and polymers including PTFE, polyamides $[184,185]$. Solid lubricants such as $\mathrm{MoS}_{2}$, carbon black, graphite in addition to nanometric scale carbon fibers, titanium, and many more have been investigated with varying composition and a variety of manufacturing parameters, namely sintering temperature and powder size to determine solid-lubricant films with advanced tribological properties and reliability for industrial applications $[21,169,186]$. Figure 17 correlated the film coverage and friction coefficient as a function of solid-lubricant content for $\mathrm{MoS}_{2}$ films. A substantial number of publications has reported a variety of combination of different solid lubricants and their matrices to generate the best possible solid-lubricant films. Table 4 summarizes some pioneering work that used matrix composites for solid lubrication in the past two decades.

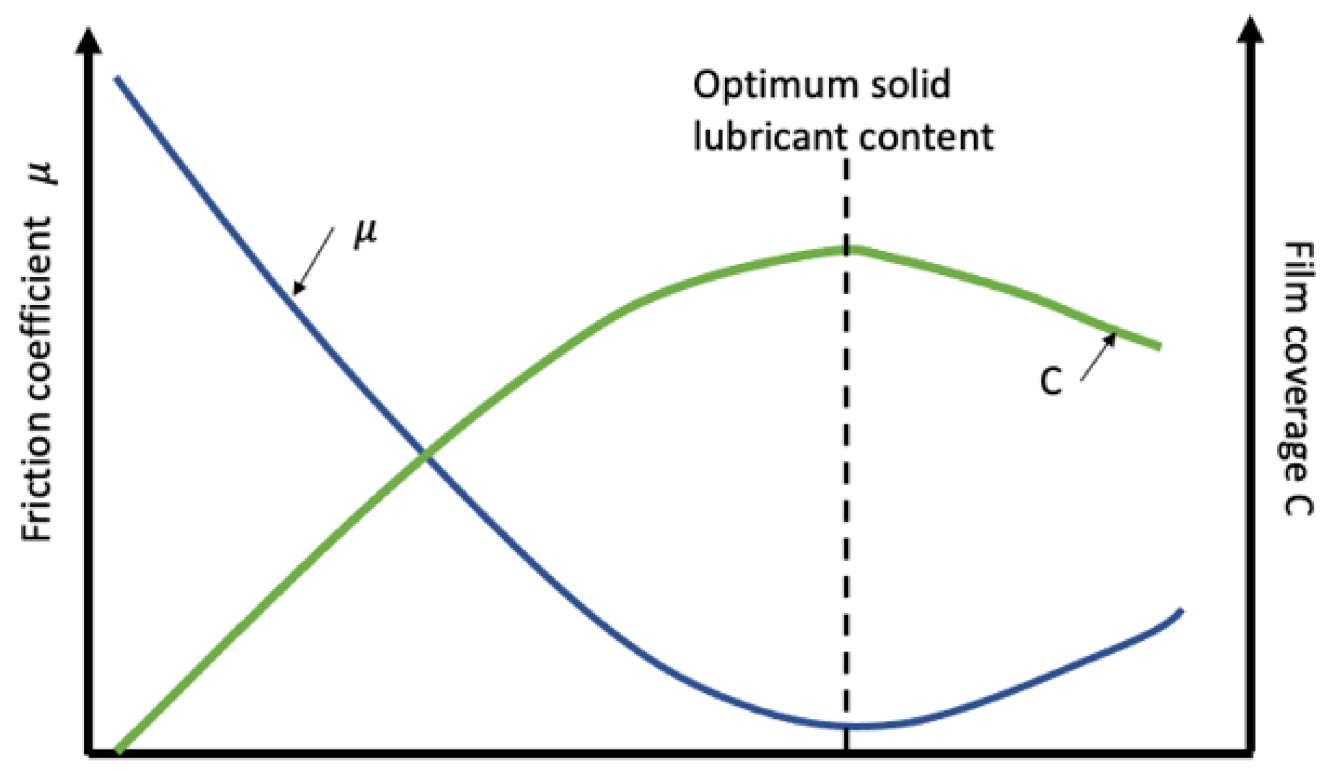

Lubricant content

Figure 17. Relationship between film coverage and friction coefficient as a function of solid-lubricant content for $\mathrm{MoS}_{2}$ films [21].

Lightweight components are the biggest needs of automobile and aircraft industries that remain a challenge to this date. Aluminum and titanium have been explored as an alternative to heavy-duty steel to produce machine parts $[187,188]$. Reinforcement of metals and alloys along with solid lubricants, hard ceramic particles, and fibers have been an area of interest in the development of MMC with precise balances of mechanical, physical and tribological characteristics $[189,190]$. Metal matrix composites reinforced with carbon, polymer, or ceramic fibers with varying compositions of solid-lubricant content have been investigated extensively for spacecraft applications [21]. $\mathrm{MoS}_{2}$, as the most successful solid lubricant in space applications, has gained a lot of eminence in the field of solid-lubrication research. Additionally, some investigations reported the use of $\mathrm{Ni}$, WC, c-BN, and graphite solid-lubrication coatings on softer materials such as aluminum alloys to increase the surface hardness [190-192]. By contrast, the focus of automobile industries has primarily been on mixed lubrication, which is the combination of solid and liquid lubricants to address their tribological focused challenges.

A considerable amount of work has been conducted on copper, iron, nickel, and aluminum metal matrix composites with $\mathrm{MoS}_{2}$ as the primary lubricating material [193]. The high thermal and electrical conductivity of copper has led to its applications in electrical contacts, bearings, slide blocks, bushes, and other friction materials. Copper is known to be reactive toward $\mathrm{MoS}_{2}$ that results in the formation of $\mathrm{Cu}-\mathrm{Mo}$ mixed sulfides that deteriorate the strength and tribological properties [194]. Addition of al- 
loying elements in $\mathrm{Cu}$ to form brass and bronze helps in overcoming the reactivity of $\mathrm{MoS}_{2}$ with $\mathrm{Cu}$ [195-197]. Iron and steel have been dominating the manufacturing and automobile industries since the industrial revolution ( 1800 AD), particularly steels due to their high resistance against corrosion, fatigue, and wear. The reliability and availability of different grades of steel powders $[198,199]$ have led to advancement of sintered steels that are further alloyed with elements and ceramics to control the chemical composition and the processing parameters, to achieve iron-based MMC with enhanced compressibility, machinability, hardness, strength, and toughness [200,201]. Nickel is used in matrix for high-temperature applications such as turbine engines, radiator systems, and nuclear reactors $[202,203]$. The use of solid lubricants for high-temperature applications is challenging, and therefore, MMC containing Ni matrix comprising of two or more solid lubricants such as graphite, $\mathrm{Ti}_{3} \mathrm{SiC}_{2} \mathrm{WS}_{2}$, and $\mathrm{PbO}[204,205]$ is used for lubrication at a wide range of temperature applications [206]. In recent times, aluminum and titanium have gained attention as a potential solid-lubricating matrix due to their light weight and specific strength $[207,208]$. Some investigations have reported the use of a silver matrix for the lubrication of electrical contacts $[209,210]$.

Ceramic materials are known for their high-temperature stability and chemical inertness. Solid-lubricant powders possessing high thermal stability such as $\mathrm{BaF}_{2}, \mathrm{CaF}_{2}$, $\mathrm{SrSO}_{4}$, and $\mathrm{CaSiO}_{3}$ are mixed with ceramic powders such as $\mathrm{ZrO}_{2}, \mathrm{Y}_{2} \mathrm{O}_{3}, \mathrm{Al}_{2} \mathrm{O}_{3}$, and $\mathrm{TiC}$, and sintered at high temperature and pressure to produce lubricious ceramic composites [211-213]. Ouyanga et al., found that unlubricated $\mathrm{ZrO}_{2}\left(\mathrm{Y}_{2} \mathrm{O}_{3}\right)-\mathrm{Al}_{2} \mathrm{O}_{3}$ has a friction coefficient of 1.15 and a wear rate in the order of $10-4 \mathrm{~mm}^{3} \mathrm{~N}^{-1} \mathrm{~m}^{-1}$ at $800{ }^{\circ} \mathrm{C}$ [211]. The addition of $\mathrm{SrSO}_{4}$ reduces the brittleness of the ceramic matrix and facilitates plastic deformation. It is also reported that the effective spreading of lubricating material over the ceramic matrix is responsible for reducing the friction and wear over a wide range of temperatures. The size of the ceramic powder and sintering temperatures also affects the tribological performance [211,214,215].

Solid lubrication using polymeric materials such as polyamides, PMMA (Polymethyl methacrylate), and PTFE (Polytetrafluoroethylene) have also been used as a lubricating matrix in automobile body parts. The manufacturing feasibility arising with the addition of nanofibers enhances strength, and the presence of solid lubricants reduces friction, which has further prompt investigations on the applications polymer matrix composites [216]. The discovery of polymer nanocomposites and graphene has led to an interest in developing polymer/graphene nanocomposites with superior mechanical, thermal, gas barrier, electrical, and tribological properties [217,218]. A significant number of reports are centered on various polymer nanocomposites and the impact of fiber reinforcement and lubricant that influences on the tribological performance [219-223]. 
Table 4. Some publications on using matrix composites for solid lubrication from 2000 to 2020.

\begin{tabular}{|c|c|c|c|c|}
\hline Publication & Matrix & Lubricant & Parameters & Important Findings \\
\hline Chen et al., 2008 [150] & Copper & $\begin{array}{l}\text { - Graphite from } 10 \text { wt. } \% \text { to } \\
0 \text { wt. } \% \\
\text { h-BN from } 0 \text { wt. } \% \text { to } 10 \\
\text { wt. } \%\end{array}$ & $\begin{array}{l}\text { - } \quad \text { Block-on-ring wear tester } \\
\text { beanter surface: AISI52100 } \\
\text { bearing steel }\end{array}$ & $\begin{array}{l}\text { - The lubrication effects of graphite are superior to those } \\
\text { of h-BN. } \\
\text { Added graphite with low contents of h-BN can } \\
\text { stabilize friction and wear properties } \\
\text { - COF increased from } 0.35 \text { to } 0.55 \text { with an increase in } \\
\text { load from } 50 \text { to } 125 \mathrm{~N}\end{array}$ \\
\hline Tang et al., 2011 [224] & Copper & $\mathrm{NbSe}_{2}$ nanofiber & $\begin{array}{l}\text { - } \quad \text { Ball-on-disk, } 50-70 \% \text { RH } \\
\text { - Counter surface: } 440-\mathrm{C} \\
\text { stainless steel }\end{array}$ & $\begin{array}{l}\text { - } 15 \text { wt. } \% \mathrm{NbSe}_{2} \text { nanofibers showed a very low } \\
\text { coefficient of friction of } 0.1487\end{array}$ \\
\hline Zhang et al., 2019 [225] & Copper & $\mathrm{Ni} / \mathrm{NbSe}_{2}$ & $\begin{array}{ll}\text { - } & \text { Ball-on-disk } \\
\text { Counter surface: GCr15 }\end{array}$ & $\begin{array}{l}\text { - } 15 \mathrm{wt} . \% \mathrm{Ni} / \mathrm{NbSe}_{2} \text { showed the lowest friction coefficient } \\
(0.16) \text { and wear rate }\left(4.1 \times 10^{-5} \mathrm{~mm}^{3} \mathrm{~N}^{-1} \mathrm{~m}^{-1}\right)\end{array}$ \\
\hline $\begin{array}{l}\text { Sundararajan et al. } \\
2016[226]\end{array}$ & $\begin{array}{l}\mathrm{Cu}-\mathrm{X} \mathrm{SiC} \text { wt. } \%(X=0 \\
5,10, \text { and } 15 \text { wt. } \%)\end{array}$ & Gr at 5 and $10 \mathrm{wt} . \%$ & - $\quad$ Pin-on-disc & - $\quad 10$ wt.\% gr and 15 wt.\% SiC best result \\
\hline Prabhu et al., 2015 [227] & $\mathrm{Cu}-20$ vol. $\%$ silica & $\begin{array}{l}10 \text { vol. } \% \text { of } \mathrm{MoS}_{2} \\
\text { or graphite } \\
\text { or h-BN }\end{array}$ & $\begin{array}{l}\text { - } \quad \text { Disc-on-pad dynamometer, } 70 \% \mathrm{RH} \\
\text { - Counter surface: gray cast iron disc }\end{array}$ & $\begin{array}{l}\text { - } \mathrm{MoS}_{2} \text { is the most effective lubricant with } \mathrm{COF}= \\
0.18-0.3 \text { for sliding speed for } 3-9 \mathrm{~m} / \mathrm{s} \text { followed by, } \\
\text { graphite, and h-BN }\end{array}$ \\
\hline $\begin{array}{l}\text { Zhen et al. } \\
2017[228]\end{array}$ & Nickel & $\begin{array}{c}\mathrm{Ag}=12.5 \text { wt. } \% \\
\mathrm{Baf}_{2} / \mathrm{CaF}_{2}=5 \text { wt. } \% \\
\text { Graphite }=0,0.5,1,2 \text { wt. } \%\end{array}$ & $\begin{array}{l}\text { - } \quad \text { Ball-on-disk, } \mathrm{RT} \text { to } 800^{\circ} \mathrm{C} \\
\text { - } \quad \text { Counter surface: Si3N4 ceramic ball }\end{array}$ & $\begin{array}{l}\text { - } \quad 0.5 \text { wt. } \% \text { graphite exhibited the lowest } \mathrm{COF} \text { at different } \\
\text { testing temperatures except at } 800^{\circ} \mathrm{C} \text {. } \\
\text { - The composite with } 2.0 \text { wt. } \% \text { graphite showed the } \\
\text { lowest at } 800{ }^{\circ} \mathrm{C}\end{array}$ \\
\hline $\begin{array}{l}\text { Zhao et al. } \\
2019[229]\end{array}$ & Nickel & $\begin{array}{l}\text { h-BN=1.25 wt. } \% \\
\text { nano-Carbon = } 5 \text { wt. } \%\end{array}$ & $\begin{array}{l}\text { - Experiments conducted from } \\
25^{\circ} \mathrm{C}-500^{\circ} \mathrm{C}\end{array}$ & $\begin{array}{l}\text { - The encapsulation of h-BN with nano-Cu increased the } \\
\text { h-BN content in the coating } \\
\text { - COF reduced from } 0.48 \text { to } 0.35 \text { from } 25{ }^{\circ} \mathrm{C} \text { to } 500{ }^{\circ} \mathrm{C}\end{array}$ \\
\hline $\begin{array}{l}\text { Chen et al. } \\
2018[230]\end{array}$ & Ni Cr 80-20 wt.\% & $\begin{array}{l}\mathrm{MoS}_{2} \\
\text { Graphite }\end{array}$ & $\begin{array}{l}\text { - } \quad \text { Pin-on-disk } \\
\text { Counter surface: steel disk } \\
(\mathrm{Cr} 12 \mathrm{MoV})\end{array}$ & $\begin{array}{l}\text { - } 10 \% \mathrm{MoS}_{2}+\mathrm{Ni}+\mathrm{Cr}(80-20 \text { wt. } \%) \text { showed best result } \\
\text { with } \mathrm{COF}=0.02\end{array}$ \\
\hline
\end{tabular}


Table 4. Cont.

\begin{tabular}{|c|c|c|c|c|}
\hline Publication & Matrix & Lubricant & Parameters & Important Findings \\
\hline Huang et al., 2017 [231] & $\begin{array}{l}\text { WC-Ni-Cr88 wt. } \% \text { WC, } \\
11 \text { wt. } \% \mathrm{Ni} \text { and } \\
1 \text { wt. } \% \mathrm{Cr}\end{array}$ & $\mathrm{WS}_{2}=5 \mathrm{wt} . \%$ & $\begin{array}{l}\text { - } \quad \text { Ball-on-disk } \\
\text { Counter surfaces: WC-Ni balls }\end{array}$ & $\begin{array}{l}\text { - Composite sintered at } 950^{\circ} \mathrm{C} \text { under } 250 \mathrm{MPa} \text { showed } \\
\text { best } \mathrm{COF}=0.13\end{array}$ \\
\hline $\begin{array}{l}\text { Kulka et al. } \\
2019[232]\end{array}$ & $\mathrm{Ni}$ & $\mathrm{CaF}_{2} 20 \%$ & $\begin{array}{l}\text { - } \quad \text { Pin-on-disc Counter surface: } \\
\text { - Inconel 625-alloy }\end{array}$ & - $\mathrm{COF}=0.75$ to 0.45 from room to $600^{\circ} \mathrm{C}$ \\
\hline Gupta et al., 2019 [233] & $\begin{array}{l}\text { Fe-0.3C-2Ni based } \\
\text { composites }\end{array}$ & $\mathrm{WS}_{2}(3,5,7$ and 9 wt. $\%)$ & & $\begin{array}{l}\text { - The composite with the highest amount of } \mathrm{WS}_{2}(9 \\
\text { wt.\%) showed the lowest coefficient of friction (0.47) }\end{array}$ \\
\hline $\begin{array}{l}\text { Zalaznik et al., } 2016 \\
{[\text { [234] }}\end{array}$ & PEEK & micro and nano $\mathrm{MoS}_{2}, \mathrm{WS}_{2}$ & $\begin{array}{l}\text { - } \quad \text { Pin-on-disc } \\
\text { Counter surface: stainless steel pin } \\
\text { (100Cr6). }\end{array}$ & $\begin{array}{l}\text { - Friction reduced from } 0.6 \text { to } 0.4 \text { with the addition of } \\
\text { micro and nano } \mathrm{MoS}_{2}, \mathrm{WS}_{2}\end{array}$ \\
\hline Cura et al., 2013 [235] & $\begin{array}{c}\mathrm{Al}_{2} \mathrm{O}_{3}-15 \mathrm{wt} . \% \mathrm{ZrO}_{2} \\
\text { (AZ) }\end{array}$ & $\begin{array}{l}3 \text { wt. } \% \text { of } \mathrm{CaF}_{2}, \mathrm{BaF}_{2}, \mathrm{MoS}_{2} \\
\mathrm{WS}_{2}, \mathrm{~h}-\mathrm{BN} \text {, or graphite }\end{array}$ & - $\quad$ Scratch testing at $27 \mathrm{~N}$ & $\begin{array}{ll}\text { - } & \mathrm{AZCOF}=0.068 \\
\text { - } & \mathrm{CaF}_{2} \mathrm{COF}=0.043 \\
\text { - } & \mathrm{BaF}_{2} \mathrm{COF}=0.082 \\
\text { - } & \mathrm{MoS}_{2} \mathrm{COF}=0.086 \\
\text { - } & \mathrm{WS}_{2} \mathrm{COF}=0.093 \\
\text { - } & \mathrm{h}-\mathrm{BN} \mathrm{COF}=0.086 \\
\text { - } & \mathrm{Graphite} \mathrm{COF}=0.121\end{array}$ \\
\hline $\begin{array}{l}\text { Ali et al. } \\
2019[236]\end{array}$ & M50 steel & $\begin{array}{c}\mathrm{TiO}_{2} 10 \text { wt. } \% \\
\mathrm{TiO}_{2} / \mathrm{G} \text { powder }(10 \text { wt. } \% \\
\left.\mathrm{TiO}_{2}+5 \text { wt. } \% \mathrm{G}\right)\end{array}$ & $\begin{array}{l}\text { - } \quad \text { Pin-on-disk } \\
\text { Counter surfaces: Si3N4 balls }\end{array}$ & $\begin{array}{l}\text { - The tribological performance of } \mathrm{TiO}_{2} / \mathrm{G} \text { was the best } \\
\text { - } \quad \text { It decreased from } 0.43 \text { to } 0.2 \text { from } 25-450{ }^{\circ} \mathrm{C} \\
\text { - } \quad \text { Pure M50 had a COF of } 0.8\end{array}$ \\
\hline $\begin{array}{l}\text { Tao et al. } \\
2001[237]\end{array}$ & Tin-bronze & Graphite, $\mathrm{MoS}_{2}$ or PTFE & $\begin{array}{ll}- & \text { Contact pressure }=5 \mathrm{MPa} \\
- & \text { Sliding velocity }=0.16 \mathrm{~m} / \mathrm{s} \\
\text { - } & \text { Testing time }=8 \mathrm{~h}\end{array}$ & $\begin{array}{l}\text { - PTFE } 20 \mathrm{wt} . \% \text { and graphite } 40 \mathrm{wt} . \% \text {. showed the best } \\
\text { result with COF=0.13 } \\
\text { Wear rate also reduced by three orders of magnitude } \\
\text { for the above sample }\end{array}$ \\
\hline $\begin{array}{l}\text { Mushtaq et al. } 2018 \\
{[238]}\end{array}$ & $\begin{array}{l}\mathrm{Fe}-\mathrm{Cu} 5 \text { wt. } \%- \\
\quad \mathrm{Sn} 3 \text { wt. } \%\end{array}$ & $\mathrm{MoS}_{2}(0-3$ wt. $\%)$ & $\begin{array}{l}\text { - } \quad \text { Ball-on-disc } \\
\text { - Counter surface EN-8 steel }\end{array}$ & $\begin{array}{l}\text { - Increasing } \mathrm{MoS}_{2} \text { content from } 0 \text { to } 3 \mathrm{wt} . \% \text { the } \\
\text { coefficient of friction decreased from } 0.85 \text { to } 0.25 \text {. }\end{array}$ \\
\hline
\end{tabular}




\section{Conclusions}

The importance and current research on solid-film lubrication have been extensively reviewed to provide a holistic understanding of its importance, advantages, and limitations regarding its application in the industry. The effect of various alloying elements, manufacturing processes, and associated process parameters on the tribological performance of solid lubricants, such as carbon-based and molybdenum-based compounds, is discussed from both a theoretical and experimental investigation standpoint. Molybdenum-based compounds are used extensively in astronomical and aeronautical applications; however, the lubricating property of $\mathrm{MoS}_{2}$ is susceptible to atmospheric humidity. On the contrary, carbon-based solid lubricants are known for their advanced tribological performance under humid conditions due to the weakening of interlayer Van der Waals bonds due to saturation of $\mathrm{H}^{+}$and $\mathrm{OH}^{-}$ions from water, which facilitates their interlayer cleavage. A comprehensive review on 2D materials like h-BN, boric acid, and black phosphorous is also covered from an application perspective due to their recent prominence in the literature. Based on the high thermal stability of h-BN, it is deemed the preferred primary lubricant to produce lubricious matrix composites at higher sintering temperatures. Boric acid requires replenishment at intervals, and therefore, used multifunctional solid and ionic liquid lubricants involved in the dispersion of boric acid in liquid lubricants. Black phosphorous is used in lubricious polymeric matrix composites for bearing cages, gears, and cams in the automobile industry. The exploitation of powder metallurgy and sintering methods to produce ceramic and metal matrix composites for high-temperature, corrosion-resistant, and high-wear applications is also discussed. Notable case studies on sputter-deposited and sintered solid-lubricant composites, with reported values of coefficient of friction and environmental conditions, are summarized in tables and graphs for easy readability and understanding.

Solid lubricants possess different desirable properties in comparison with liquids. The higher working range and lubricating properties for extreme conditions are the biggest advantages in commercial applications. However, the lower wear life and difficulty in recoating are the biggest challenges for being considered as a replacement of liquid lubricants. Some solid lubricants such as diamond-like carbon coatings are used along with liquid lubricants to provide better lubricant performance. The present market for solid lubricants is still on extreme condition lubrication, but solid-lubricant nanocomposite coatings have gained some momentum in high-performance industrial applications, such as in mining and wind turbines. Solid-lubricant coatings can be used for many applications when liquid lubricants alone cannot provide the required lubrication need. The increased demand for green or environment-friendly energy systems such as electric engines and wind energy harvesters will lead to the increased use of solid lubricants, as some additives in oil lubricants are known to be environmentally hazardous.

Author Contributions: Authors B.R.M. and A.H.J. have analyzed the data and literature, and prepared this manuscript. A.G. inspected the content and involved in reviewing the content. This manuscript was prepared only for the educational purpose. All authors have read and agreed to the published version of the manuscript.

Funding: This research received no external funding.

Institutional Review Board Statement: Not applicable.

Informed Consent Statement: Not applicable.

Data Availability Statement: Data sharing is not applicable for this article.

Acknowledgments: One of the authors, B.R.M., would like to acknowledge the financial assistance given by the University of Toledo for this study.

Conflicts of Interest: The authors declare no conflict of interest. 


\section{References}

1. Holmberg, K.; Siilasto, R.; Laitinen, R.T.; Andersson, P.; Jäsberg, A. Global energy consumption due to friction in paper machines. Tribol. Int. 2013, 62, 58-77. [CrossRef]

2. Holmberg, K.; Andersson, P.; Nylund, N.O.; Mäkelä, K.; Erdemir, A. Global energy consumption due to friction in trucks and buses. Tribol. Int. 2014, 78, 94-114. [CrossRef]

3. Holmberg, K.; Erdemir, A. Global impact of friction on energy consumption, economy and environment. FME Trans. 2015, 43, 181-185.

4. Holmberg, K.; Andersson, P.; Erdemir, A. Global energy consumption due to friction in passenger cars. Tribo. Int. 2012, 47, 221-234. [CrossRef]

5. Holmberg, K.; Erdemir, A. Influence of tribology on global energy consumption, costs and emissions. Friction 2017, 5, 263-284. [CrossRef]

6. Dowson, D. History of Tribology, 2nd ed.; Longman: London, NY, USA, 1979.

7. Tichy, J.A.; Meyer, D.M. Review of solid mechanics in tribology. Int. J. Solids Struct. 2000, 37, 391-400. [CrossRef]

8. Bermúdez, M.D.; Jiménez, A.E.; Sanes, J.; Carrión, F.J. Ionic liquids as advanced lubricant fluids. Molecules 2009, 14, 2888-2908. [CrossRef] [PubMed]

9. Peterson, M.B.; Murray, S.F.; Florek, J.J. Consideration of lubricants for temperatures above 1000 F. ASLE Trans. 1959, 2, 225-234. [CrossRef]

10. Spalvins, T. A review of recent advances in solid film lubrication. J. Vac. Sci. Technol. A 1987, 5, 212-219. [CrossRef]

11. Miyoshi, K. Solid Lubricants and Coatings for Extreme Environments: State-of-the-Art Survey. NASA/TM 2007, $214668,1-16$.

12. Shah, F.U.; Glavatskih, S.; Antzutkin, O.N. Boron in tribology: From borates to ionic liquids. Tribol. Lett. 2013, 51, 281-301. [CrossRef]

13. Scharf, T.W.; Prasad, S.V. Solid lubricants: A review. J. Mat. Sci. 2013, 48, 511-531. [CrossRef]

14. Mannix, A.J.; Kiraly, B.; Hersam, M.C.; Guisinger, N.P. Synthesis and chemistry of elemental 2D materials. Nat. Rev. Chem. 2017, 1.2, 1-14. [CrossRef]

15. Guo, S.; Dong, S. Graphene nanosheet: Synthesis, molecular engineering, thin film, hybrids, and energy and analytical applications. Chem. Soc. Rev. 2011, 40, 2644-2672. [CrossRef]

16. Winer, W.O. Molybdenum disulfide as a lubricant: A review of the fundamental knowledge. Wear 1967, 10, 422-452. [CrossRef]

17. Mbamara, U.S.; Olofinjana, B.; Ajayi, O.O.; Lorenzo-Martin, C.; Obiajunwa, E.I.; Ajayi, E.O.B. Friction and wear behavior of nitrogen-doped $\mathrm{ZnO}$ thin films deposited via MOCVD under dry contact. Eng. Sci. Technol. Int. J. 2016, 19, 956-963. [CrossRef]

18. Saito, T.; Honda, F. Chemical contribution to friction behavior of sintered hexagonal boron nitride in water. Wear 2000, 237, 253-260. [CrossRef]

19. Zhan, H.; Guo, D.; Xie, G.X. Two-dimensional layered materials: From mechanical and coupling properties towards applications in electronics. Nanoscale 2019, 11, 13181-13212. [CrossRef]

20. Zhang, P.; Wang, F.; Yu, M.; Zhuang, X.; Feng, X. Two-dimensional materials for miniaturized energy storage devices: From individual devices to smart integrated systems. Chem. Soc. Rev. 2018, 47, 7426-7451. [CrossRef] [PubMed]

21. Furlan, K.P.; De Mello, J.D.B.; Klein, A.N. Self-lubricating composites containing MoS2: A review. Tribol. Int. 2018, 120, 280-298. [CrossRef]

22. Chen, Z.; He, X.; Xiao, C.; Kim, S. Effect of Humidity on Friction and Wear-A Critical Review. Lubricants 2018, 6, 74. [CrossRef]

23. Zang, X.; Zhou, Q.; Chang, J.; Liu, Y.; Lin, L. Graphene and carbon nanotube (CNT) in MEMS/NEMS applications. Microelectron. Eng. 2015, 132, 192-206. [CrossRef]

24. Pu, J.; Mo, Y.; Wan, S.; Wang, L. Fabrication of novel graphene-fullerene hybrid lubricating films based on self-assembly for MEMS applications. Chem. Commun. 2014, 50, 469-471. [CrossRef] [PubMed]

25. Adams, J.B.; Hector, L.G.; Siegel, D.J.; Yu, H.; Zhong, J. Adhesion, lubrication and wear on the atomic scale. Surf. Interf. Analy. 2001, 31, 619-626. [CrossRef]

26. Bhushan, B.; Israelachvili, J.N.; Landman, U. Nanotribology: Friction, wear and lubrication at the atomic scale. Nature 1995, 374, 607-616. [CrossRef]

27. Bhushan, B. Nanotribology and nanomechanics. Wear 2005, 259, 1507-1531. [CrossRef]

28. Berman, D.; Erdemir, A.; Sumant, A.V. Approaches for Achieving Superlubricity in Two-Dimensional Materials. ACS Nano. 2018, 12, 2122-2137. [CrossRef]

29. Hutchings, I.; Shipway, P. Tribology: Friction and Wear of Engineering Materials, 2nd ed.; Butterworth-Heinemann: Oxford, UK, 2017.

30. Aquaro, D.; Fontani, E. Erosion of ductile and brittle materials. Meccanica 2001, 36, 651-661. [CrossRef]

31. Rice, J.R. Fracture mechanics. Appl. Mech. Rev. 1985, 38, 1271-1275. [CrossRef]

32. Qiu, B.; Xing, S.; Dong, Q. Green preparation and dry sliding wear properties of a macro-ZTA/fe composite produced by a two-step method. Metals 2019, 9, 986. [CrossRef]

33. Scarpa, F.; Adhikari, S.; Chowdhury, R. The transverse elasticity of bilayer graphene. Phys. Lett. A 2010, 374, 2053-2057. [CrossRef]

34. Smolyanitsky, A.; Killgore, J.P. Anomalous friction in suspended graphene. Available online: https://arxiv.org/abs/1207.5173 (accessed on 16 March 2021). 
35. Zhang, L.; Tanaka, H. Towards a deeper understanding of wear and friction on the atomic scale-A molecular dynamics analysis. Wear 1997, 211, 44-53. [CrossRef]

36. Riedo, E.; Gnecco, E.; Bennewitz, R.; Meyer, E.; Brune, H. Interaction Potential and Hopping Dynamics Governing Sliding Friction. Phys. Rev. Lett. 2003, 91, 084502. [CrossRef]

37. Krylov, S.Y.; Frenken, J.W.M. The physics of atomic-scale friction: Basic considerations and open questions. Phys. Status Solidi B 2014, 251, 711-736. [CrossRef]

38. Smolyanitsky, A. Effects of thermal rippling on the frictional properties of free-standing graphene. RSC Adv. 2015, 5, 29179-29184. [CrossRef]

39. Padmavathi, D.A. Potential Energy Curves \& Material Properties. Mat. Sci. Appl. 2011, 2, 97-104.

40. Li, J.; Luo, J. Superlow Friction of Graphite Induced by the Self-Assembly of Sodium Dodecyl Sulfate Molecular Layers. Langmuir 2017, 33, 12596-12601. [CrossRef] [PubMed]

41. Deng, Z.; Smolyanitsky, A.; Li, Q.; Feng, X.Q.; Cannara, R.J. Adhesion-dependent negative friction coefficient on chemically modified graphite at the nanoscale. Nat. Mater. 2012, 11, 1032-1037. [CrossRef] [PubMed]

42. Truong-Son, N. Gibbs Free Energy. Why Are Equilibrium Constants for a Chemical Reaction Temperature Dependent? 17 March. Available online: socrat-ic.org/questions/gibbs-free-energy-why-are-equilibrium-constants-for-a-chemical-reaction-temperat (accessed on 17 March 2021).

43. Manu, B.R.; Jayatissa, A.H. Effect of Humidity on Friction of Molybdenum Disulfide Films Produced by Thermal Evaporation on Titanium Substrates. Chem. Sci. Int. J. 2020, 29, 25-33. [CrossRef]

44. Gallagher, P.; Lee, M.; Taniguchi, T.; Goldhaber-Gordon, D. Switchable friction enabled by nanoscale self-assembly on graphene. Nat. Commun. 2016, 7, 10745. [CrossRef]

45. Manu, B.R.; Schroeder, A.M.; Jayatissa, A.H. Characterization of the Effect of Moisture on Tribology of Titanium Rubbed Against Different Pin Materials. Chem. Sci. Int. J. 2020, 29, 1-10. [CrossRef]

46. Manimunda, P.; Al-Azizi, A.; Kim, S.H.; Chromik, R.R. Shear-Induced Structural Changes and Origin of Ultralow Friction of Hydrogenated Diamond-like Carbon (DLC) in Dry Environment. ACS Appl. Mater. Interf. 2017, 9, 16704-16714. [CrossRef] [PubMed]

47. Heimberg, J.A.; Wahl, K.J.; Singer, I.L.; Erdemir, A. Superlow friction behavior of diamond-like carbon coatings: Time and speed effects. Appl. Phys. Lett. 2001, 78, 2449-2451. [CrossRef]

48. Kurahashi, Y.; Tanaka, H.; Terayama, M.; Sugimura, J. Effects of environmental gas and trace water on the friction of DLC sliding with metals. Micromachines 2017, 8, 217. [CrossRef]

49. Donnet, C.; Erdemir, A. Tribology of Diamond-Like Carbon Films: Fundamentals and Applications, 1st ed.; Springer Sci. Bus: New York, NY, USA, 2008.

50. Bhowmick, S.; Banerji, A.; Alpas, A.T. Role of humidity in reducing sliding friction of multilayered graphene. Carbon 2015, 87 , 374-384. [CrossRef]

51. Ohmae, N. Humidity effects on tribology of advanced carbon materials. Tribol. Int. 2006, 39, 1497-1502. [CrossRef]

52. Arif, T.; Colas, G.; Filleter, T. Effect of Humidity and Water Intercalation on the Tribological Behavior of Graphene and Graphene Oxide. ACS Appl. Mater. Interf. 2018, 10, 22537-22544. [CrossRef]

53. Theiler, G.; Gradt, T.; Österle, W.; Brückner, A.; Weihnacht, V. Friction and endurance of $\mathrm{MoS}_{2} /$ ta-C coatings produced by Laser Arc deposition. Wear 2013, 297, 791-801. [CrossRef]

54. Berman, D.; Erdemir, A.; Sumant, A.V. Few layer graphene to reduce wear and friction on sliding steel surfaces. Carbon 2013, 54, 454-459. [CrossRef]

55. Shi, Z.; Shum, P.; Wasy, A.; Zhou, Z.; Li, L.K.Y. Tribological performance of few layer graphene on textured M2 steel surfaces. Surf. Coat. Technol. 2016, 296, 164-170. [CrossRef]

56. Berman, D.; Erdemir, A.; Sumant, A.V. Reduced wear and friction enabled by graphene layers on sliding steel surfaces in dry nitrogen. Carbon 2013, 59, 167-175. [CrossRef]

57. Penkov, O.; Kim, H.J.; Kim, H.J.; Kim, D.E. Tribology of graphene: A review. Int. J. Precis. Eng. Manuf. 2014, 15, 577-585. [CrossRef]

58. Ko, J.H.; Kwon, S.; Park, B.H.; Park, J.Y. Nanotribological properties of fluorinated, hydrogenated, and oxidized graphenes. Tribol. Lett. 2013, 50, 137-144. [CrossRef]

59. Berman, D.; Deshmukh, S.A.; Sankaranarayanan, S.K.R.S.; Erdemir, A.; Sumant, A.V. Extraordinary Macroscale Wear Resistance of One Atom Thick Graphene Layer. Adv. Funct. Mater. 2014, 24, 6640-6646. [CrossRef]

60. Kwon, S.; Ko, J.H.; Jeon, K.J.; Kim, Y.H.; Park, J.Y. Enhanced nanoscale friction on fluorinated graphene. Nano Lett. 2012, 12, 6043-6048. [CrossRef] [PubMed]

61. Kim, K.S.; Kim, J.H.; Ahn, J.H.; Lee, H.J. Chemical vapor deposition-grown graphene: The thinnest solid lubricant. ACS Nano. 2011, 5, 5107-5114. [CrossRef] [PubMed]

62. Wang, L.F.; Ma, T.B.; Hu, Y.Z.; Wang, H. Atomic-scale friction in graphene oxide: An interfacial interaction perspective from first-principles calculations. Phys. Rev. B 2012, 86, 1-9. [CrossRef]

63. Wang, J.; Song, Y.; Sun, Q.; Jia, Y. Theoretical study of superlow friction between two single-side hydrogenated graphene sheets. Tribol. Lett. 2012, 48, 255-261. [CrossRef] 
64. Lin, T.W.; Modafe, A.; Shapiro, B.; Ghodssi, R. Characterization of dynamic friction in MEMS-based microball bearings. IEEE Trans. Instrum. Meas. 2004, 53, 839-846. [CrossRef]

65. Ghalichechian, N.; Modafe, A.; Beyaz, M.; Waits, C.M.; Ghodssi, R. Design and Fabrication of a Rotary Electrostatic Micromotor Supported on Microball Bearings. Sixth Int. Work. Micro Nanotechnol. Power Gener. Energy Convers. Appl. 2006, 6, $227-230$.

66. Liang, T.; Sawyer, W.G.; Perry, S.S.; Sinnott, S.B.; Phillpot, S.R. First-principles determination of static potential energy surfaces for atomic friction in $\mathrm{MoS}_{2}$ and $\mathrm{MoO}_{3}$. Phys. Rev. B 2008, 77, 1-6. [CrossRef]

67. Cahangirov, S.; Ataca, C.; Topsakal, M.; Sahin, H.; Ciraci, S. Frictional figures of merit for single layered nanostructures. Phys. Rev. Lett. 2012, 108, 1-5. [CrossRef]

68. Miura, K.; Sasaki, N.; Kamiya, S. Friction mechanisms of graphite from a single-atomic tip to a large-area flake tip. Phys. Rev. B 2004, 69, 1-9. [CrossRef]

69. Dienwiebel, M.; Verhoeven, G.S.; Pradeep, N.; Frenken, J.W.M.; Heimberg, J.A.; Zandbergen, H.W. Superlubricity of graphite. Phys. Rev. Lett. 2004, 92, 1-4. [CrossRef] [PubMed]

70. Ishigami, M.; Chen, J.H.; Cullen, W.G.; Fuhrer, M.S.; Williams, E.D. Atomic structure of graphene on $\mathrm{SiO}_{2}$. Nano Lett. 2007, 7, 1643-1648. [CrossRef]

71. Feng, X.; Kwon, S.; Park, J.Y.; Salmeron, M. Superlubric sliding of graphene nanoflakes on graphene. ACS Nano. 2013, 7, 1718-1724. [CrossRef] [PubMed]

72. Liu, S.W.; Wang, H.P.; Hu, Y.Z.; Luo, J. Robust microscale superlubricity under high contact pressure enabled by graphene-coated microsphere. Nat. Commun. 2017, 8, 1-8. [CrossRef]

73. Berman, D.; Deshmukh, S.A.; Sankaranarayanan, S.K.R.S.; Erdemir, A.; Sumant, A.V. Macroscale superlubricity enabled by graphene nanoscroll formation. Science 2015, 348, 1118-1122. [CrossRef] [PubMed]

74. Lee, C.; Li, Q.; Berger, H.; Carpick, R.W.; Hone, J. Frictional characteristics of atomically thin sheets. Science 2010, 328, 76-80. [CrossRef] [PubMed]

75. Paolicelli, G.; Tripathi, M.; Corradini, V.; Candini, A.; Valeri, S. Nanoscale frictional behavior of graphene on $\mathrm{SiO}_{2}$ and $\mathrm{Ni}(111)$ substrates. Nanotechnology 2015, 26, 055703. [CrossRef]

76. Ye, Z.; Tang, C.; Dong, Y.; Martini, A. Role of wrinkle height in friction variation with number of graphene layers. J. Appl. Phys. 2012, 112, 116102. [CrossRef]

77. Mohammadi, H.; Müser, M.H. Friction of wrinkles. Phys. Rev. Lett. 2010, 105, 224301. [CrossRef] [PubMed]

78. Banhart, F.; Kotakoski, J.; Krasheninnikov, A.V. Structural defects in graphene. ACS Nano. 2011, 5, 26-41. [CrossRef] [PubMed]

79. López-Polín, G.; Gómez-Herrero, J.; Gómez-Navarro, C. Confining crack propagation in defective graphene. Nano Lett. 2015, 15, 2050-2054. [CrossRef]

80. Zhang, T.; Gao, H. Toughening graphene with topological defects: A perspective. J. Appl. Mech. 2015, 82, 051001. [CrossRef]

81. Sun, X.Y.; Wu, R.; Xia, R.; Chu, X.H.; Xu, Y.J. Effects of Stone-Wales and vacancy defects in atomic-scale friction on defective graphite. Appl. Phys. Lett. 2014, 104, 183109. [CrossRef]

82. Kuila, T.; Bose, S.; Mishra, A.K.; Khanra, P.; Kim, N.H.; Lee, J.H. Chemical functionalization of graphene and its applications. Prog. Mat. Sci. 2012, 57, 1061-1105. [CrossRef]

83. Georgakilas, V.; Otyepka, M.; Bourlinos, A.B.; Zboril, R.; Kim, K.S. Functionalization of graphene: Covalent and non-covalent approaches, derivatives and applications. Chem. Rev. 2012, 112, 6156-6214. [CrossRef] [PubMed]

84. Müller, T.; Lohrmann, M.; Kässer, T.; Marti, O.; Mlynek, J.; Krausch, G. Frictional force between a sharp asperity and a surface step. Phys. Rev. Lett. 1997, 79, 5066-5069. [CrossRef]

85. Hunley, D.P.; Flynn, T.J.; Dodson, T.; Sundararajan, A.; Boland, M.J.; Strachan, D.R. Friction, adhesion, and elasticity of graphene edges. Phys. Rev. B 2013, 87, 035417. [CrossRef]

86. Egberts, P.; Ye, Z.; Liu, X.Z.; Dong, Y.; Martini, A.; Carpick, R.W. Environmental dependence of atomic-scale friction at graphite surface steps. Phys. Rev. B 2013, 88, 035409. [CrossRef]

87. Dong, Y.; Liu, X.Z.; Egberts, P.; Ye, Z.; Carpick, R.W.; Martini, A. Correlation between probe shape and atomic friction peaks at graphite step edges. Tribol. Lett. 2013, 50, 49-57. [CrossRef]

88. Li, Q.; Liu, X.Z.; Kim, S.P.; Shenoy, V.B.; Sheehan, P.E.; Robinson, J.T. Fluorination of graphene enhances friction due to increased corrugation. Nano Lett. 2014, 14, 5212-5217. [CrossRef]

89. Roberts, E.W. Thin solid lubricant films in space. Tribol. Int. 1990, 23, 95-104. [CrossRef]

90. Lewis, J.H.; McDaniel, R.H. A Test of Molybdenum Disulfide Lubricants in Radiation and Vacuum Environments. J. Lubr. Technol. 1969, 91, 390-395. [CrossRef]

91. Gradt, T.; Schneider, T. Tribological performance of $\mathrm{MoS}_{2}$ coatings in various environments. Lubricants 2016, 4, 32. [CrossRef]

92. Roberts, E.W. Ultralow friction films of $\mathrm{MoS}_{2}$ for space applications. Thin Solid Films. 1989, 181, 461-473. [CrossRef]

93. Bergmann, E.; Melet, G.; Müller, C.; Simon-Vermot, A. Friction properties of sputtered dichalcogenide layers. Tribol. Int. 1981, 14, 329-332. [CrossRef]

94. Sliney, H.E. High Temperature Solid Lubricants -When and Where to Use Them. NASA/TM 1973, X-68201.

95. Brainard, W.A. The thermal stability and friction of the disulfides, diselenides, and ditellurides of molybdenum and tungsten in vaccum (10-9 to 10-6 TORR). NASA/TN 1968, D-5141.

96. Gould, S.G.; Roberts, E.W. In-vacuo torque performance of dry-lubricated ball bearings and cryogenic temperatures. NASA/N89 1989, 23914. 
97. Yukhno, T.P.; Vvedensky, Y.V.; Sentyurikhina, L.N. Low temperature investigations on frictional behaviour and wear resistance of solid lubricant coatings. Tribol. Int. 2001, 34, 293-298. [CrossRef]

98. Hilton, M.R.; Fleischauer, P.D. Applications of solid lubricant films in spacecraft. Surf. Coat. Technol. 1992, 54, 435-441. [CrossRef]

99. Miyake, S.; Komiya, M.; Shindo, T. Boundary lubrication properties of nanoperiod solid lubricant multilayer films composed of diamond-like carbon and gold layers. Tribol. Lett. 2012, 46, 1-9. [CrossRef]

100. Voumard, P.; Savan, A.; Pflüger, E. Advances in solid lubrication with $\mathrm{MoS}_{2}$ multilayered coatings. Lubr. Sci. 2001, 13, 135-145. [CrossRef]

101. Bobzin, K.; Brögelmann, T.; Kruppea, N.C.; Basturk, S.; Hild, R. Synthesis, characterization, and tribological evaluation of HPPMS $(\mathrm{Cr} 1-\mathrm{xAl}$ x $) \mathrm{N}+\mathrm{MoS}_{\mathrm{y}}$ coatings. Surf. Coat. Technol. 2016, 308, 383-393. [CrossRef]

102. Prasad, S.V.; McDevitt, N.T.; Zabinski, J.S. Tribology of tungsten disulfide films in humid environments: The role of a tailored metal-matrix composite substrate. Wear 1999, 230, 24-34. [CrossRef]

103. Tagawa, M.; Yokota, K.; Matsumoto, K.; Fontaine, J.; Martin, J.-M. Space environmental effects on $\mathrm{MoS}_{2}$ and diamond-like carbon lubricating films: Atomic oxygen-induced erosion and its effect on tribological properties. Surf. Coat. Technol. 2007, 202, 1003-1010. [CrossRef]

104. Gustavsson, F. Triboactive Component Coatings: Tribological Testing and Microanalysis of Low-Friction Tribofilms. PhD Diss. Acta Universitatis Upsaliensis, Uppsala, Sweden, 2013.

105. Curry, J.F.; Argibay, N.; Babuska, T.; Nation, B.; Martini, A.; Strandwitz, N.C.; Krick, B.A. Highly Oriented MoS 2 Coatings: Tribology and Environmental Stability. Tribol. Lett. 2016, 64, 1-9. [CrossRef]

106. Lince, J.R.; Loewenthal, S.H.; Clark, C.S. Tribological and chemical effects of long-term humid air exposure on sputter-deposited nanocomposite $\mathrm{MoS}_{2}$ coatings. Wear 2019, 432, 202935. [CrossRef]

107. Fleischauer, P.D.; Lince, J.R. Comparison of oxidation and oxygen substitution in $\mathrm{MoS}_{2}$ solid film lubricants. Tribol. Int. 1999, 32, 627-636. [CrossRef]

108. Prasad, S.V.; Zabinski, J.S. Tribology of tungsten disulphide $\left(\mathrm{WS}_{2}\right)$ : Characterization of wear-induced transfer films. J. Mater. Sci. Lett. 1993, 12, 1413-1415. [CrossRef]

109. Lauwerens, W.; Wang, J.; Navratil, J.; Wieers, E.; D’haen, J.; Stals, L.M.; Bruynseraede, Y. Humidity resistant MoS(x) films prepared by pulsed magnetron sputtering. Surf. Coat. Technol. 2000, 131, 216-221. [CrossRef]

110. Fayeulle, S.; Ehni, P.D.; Singer, I.L. Analysis of transfer films formed on steel and Co-WC during sliding against $\mathrm{MoS}_{2}$-coated steel in argon. Surf. Coat. Technol. 1990, 41, 93-101. [CrossRef]

111. Dimigen, H.; Hübsch, H.; Willich, P.; Reichelt, K. Stoichiometry and friction properties of sputtered MoS layers. Thin Solid Films. 1985, 129, 79-91. [CrossRef]

112. Spalvins, T. Tribological properties of sputtered $\mathrm{MoS}_{2}$ films in relation to film morphology. Thin Solid Films. 1980, 73, 291-297. [CrossRef]

113. Ding, X.Z.; Zeng, X.T. Structural, mechanical and tribological properties of CrAlN coatings deposited by reactive unbalanced magnetron sputtering. Surf. Coat. Technol. 2005, 200, 1372-1376. [CrossRef]

114. Fox, V.; Hampshire, J.; Teer, D. $\mathrm{MoS}_{2} /$ metal composite coatings deposited by closed-field unbalanced magnetron sputtering: Tribological properties and industrial uses. Surf. Coat. Technol. 1999, 112, 118-122. [CrossRef]

115. Simmonds, M.C.; Savan, A.; Pflüger, E.; Van Swygenhoven, H. Mechanical and tribological performance of $\mathrm{MoS}_{2} \mathrm{co-sputtered}$ composites. Surf. Coat. Technol. 2000, 126, 15-24. [CrossRef]

116. Ahmed, O.; Cioc, S.; Cioc, C.; Jayatissa, A.H. Tribological Properties of Multilayer TiN and MoS 2 Thin Films. Colloid Surf. Sci. 2017, 2, 137-142.

117. Stoyanov, P.; Strauss, H.W.; Chromik, R.R. Scaling effects between micro-and macro-tribology for a Ti-MoS 2 coating. Wear 2012, 274, 149-161. [CrossRef]

118. Rigato, V.; Maggioni, G.; Boscarino, D.; Fox, V.C.; Santini, C. A study of the structural and mechanical properties of Ti-MoS 2 coatings deposited by closed field unbalanced magnetron sputter ion plating. Surf. Coat. Tech. 1999, 116, 176-183. [CrossRef]

119. Renevier, N.M.; Hamphire, J.; Fox, V.C.; Witts, J.; Allen, T.; Teer, D.G. Advantages of using self-lubricating, hard, wear-resistant $\mathrm{MoS}_{2}$-based coatings. Surf. Coat. Technol. 2001, 142, 67-77. [CrossRef]

120. Qin, X.; Ke, P.; Wang, A.; Kim, K.H. Microstructure, mechanical and tribological behaviors of MoS 2 -Ti composite coatings deposited by a hybrid HIPIMS method. Surf. Coat. Technol. 2013, 228, 275-281. [CrossRef]

121. Arslan, E.; Bülbül, F.; Alsaran, A.; Celik, A.; Efeoglu, I. The effect of deposition parameters and Ti content on structural and wear properties of $\mathrm{MoS}_{2}$ Ti coatings. Wear 2005, 259, 814-819. [CrossRef]

122. Ding, X.Z.; Zeng, X.T.; He, X.Y.; Chen, Z. Tribological properties of Cr-and Ti-doped $\mathrm{MoS}_{2}$ composite coatings under different humidity atmosphere. Surf. Coat. Technol. 2010, 205, 224-231. [CrossRef]

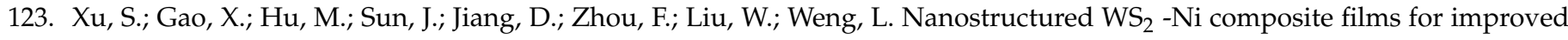
oxidation, resistance and tribological performance. Appl. Surf. Sci. 2014, 288, 15-25. [CrossRef]

124. Xu, S.S.; Weng, L.J.; Liu, Y.Z.; Kang, K.H.; Kim, C.L.; Kim, D.E. Microstructure evolution and enhanced vacuum tribological performance of Ni-doped $\mathrm{WS}_{2}$ composite coating. Surf. Coat. Technol. 2017, 325, 81-88. [CrossRef]

125. An, V.; Irtegov, Y. Tribological properties of nanolamellar $\mathrm{MoS}_{2}$ doped with copper nanoparticles. J. Nanomater. 2014, 2014, 731073. [CrossRef] 
126. Xu, S.; Weng, L.J.; Liu, Y.Z.; Kang, K.H.; Kim, D.E. Microstructure evolution and enhanced tribological properties of cu-doped $\mathrm{WS}_{2}$ films. Tribol. Lett. 2014, 55, 1-13. [CrossRef]

127. Song, W.; Xia, Z.; Pei, Y.; Ze, W.; Jun, Z.; Xing, A. Influence of negative bias voltage on the mechanical and tribological properties of $\mathrm{MoS}_{2} / \mathrm{Zr}$ composite films. J. Wuhan Univ. Technol. Mater. Sci. Ed. 2011, 26, 412-416. [CrossRef]

128. Hu, J.J.; Zabinski, J.S.; Bultman, J.E.; Sanders, J.H.; Voevodin, A.A. Structure characterization of pulsed laser deposited MoS -WSe $_{\mathrm{y}}$ composite films of tribological interests. Tribol. Lett. 2006, 24, 127-135. [CrossRef]

129. Hilton, M.R.; Bauer, R.; Didziulis, S.V.; Dugger, M.T.; Keem, J.M.; Scholhamer, J. Structural and tribological studies of MoS 2 solid lubricant films having tailored metal-multilayer nanostructures. Surf. Coat. Technol. 1992, 53, 13-23. [CrossRef]

130. Spalvins, T. Frictional and morphological properties of $\mathrm{AuMoS}_{2}$ films sputtered from a compact target. Thin Solid Films. 1984, 118, 375-384. [CrossRef]

131. Wu, Y.; Li, H.; Ji, L.; Ye, Y.; Chen, J.; Zhou, H. Preparation and properties of $\mathrm{MoS}_{2}$ /a-C films for space tribology. J. Phys. D. Appl. Phys. 2013, 46, 425301. [CrossRef]

132. Nautiyal, H.; Kumari, S.; Khatri, O.P.; Tyagi, R. Copper matrix composites reinforced by rGO-MoS 2 hybrid: Strengthening effect to enhancement of tribological properties. Compos. Part B Eng. 2019, 173, 106931. [CrossRef]

133. Watanabe, S.; Noshiro, J.; Miyake, S. Tribological characteristics of $\mathrm{WS}_{2} / \mathrm{MoS}_{2}$ solid lubricating multilayer films. Surf. Coat. Technol. 2004, 183, 347-351. [CrossRef]

134. Mikhailov, S.; Savan, A.; Hauert, R.; Swygenhoven, H.V. Morphology and tribological properties of metal (oxide)-MoS 2 nanostructured multilayer coatings. Surf. Coat. Technol. 1998, 105, 175-183. [CrossRef]

135. Li, H.; Xie, M.; Zhang, G.; Zhu, M.; Wang, L. Structure and tribological behaviour of Pb-Ti/MoS 2 nanoscaled multilayer films deposited by magnetron sputtering method. Appl. Surf. Sci. 2018, 435, 48-54. [CrossRef]

136. Renevier, N.M.; Fox, V.C.; Teer, D.G.; Hampshire, J. Coating characteristics and tribological properties of sputter-deposited $\mathrm{MoS}_{2}$ /metal composite coatings deposited by closed field unbalanced magnetron sputter ion plating. Surf. Coat. Technol. 2000, 127, 24-37. [CrossRef]

137. Savan, A.; Pflüger, E.; Goller, R.; Gissler, W. Use of nanoscaled multilayer and compound films to realize a soft lubrication phase within a hard, wear-resistant matrix. Surf. Coat. Technol. 2000, 126, 159-165. [CrossRef]

138. Miyake, S.; Shindo, T.; Saito, Y. Low friction wear resistant electroconductive gold and silver nanoperiod multilayer solid lubricant films. Tribol. Mater. Surfaces Interfaces 2011, 5, 114-120. [CrossRef]

139. Miyake, S.; Shindo, T.; Miyake, M. Deposition and Tribology of Electroconductive and Wear-Resistant Nanocomposite Solid Lubricant Films Composed of Carbon and Silver or Gold. Tribol. Lett. 2016, 61, 1-9. [CrossRef]

140. Kubart, T.; Polcar, T.; Kopecký, L.; Novák, R.; Nováková, D. Temperature dependence of tribological properties of MoS 2 and $\mathrm{MoSe}_{2}$ coatings. Surf. Coat. Technol. 2005, 193, 230-233. [CrossRef]

141. Polcar, T.; Evaristo, M.; Colaço, R.; Silviu Sandu, C.; Cavaleiro, A. Nanoscale triboactivity: The response of Mo-Se-C coatings to sliding. Acta Mater. 2008, 56, 5101-5111. [CrossRef]

142. Maharana, H.S.; Basu, A.; Mondal, K. Structural and tribological correlation of electrodeposited solid lubricating Ni-WS $\mathrm{e} 2$ composite coating. Surf. Coat. Technol. 2018, 349, 328-339. [CrossRef]

143. Domínguez-Meister, S.; Rojas, T.C.; Brizuela, M.; Sánchez-López, J.C. Solid lubricant behavior of $\mathrm{MoS}_{2}$ and WSe -based $^{-}$ nanocomposite coatings. Sci. Technol. Adv. Mater. 2017, 18, 122-133. [CrossRef]

144. Berman, D.; Erdemir, A.; Sumant, A.V. Graphene: A new emerging lubricant. Mater. Today 2014, 17, 31-42. [CrossRef]

145. Somers, A.E.; Biddulph, S.M.; Howlett, P.C.; Sun, J.; MacFarlane, D.R.; Forsyth, M. A comparison of phosphorus and fluorine containing IL lubricants for steel on aluminium. Phys. Chem. Chem. Phys. 2012, 14, 8224-8231. [CrossRef]

146. Ye, C.; Liu, W.; Chen, Y.; Yu, L. Room-temperature ionic liquids: A novel versatile lubricant. Chem. Commun. 2001, 21, 2244-2245. [CrossRef]

147. Liu, W.; Ye, C.; Gong, Q.; Wang, H.; Wang, P. Tribological performance of room-temperature ionic liquids as lubricant. Tribol. Letts. 2002, 13, 81-85. [CrossRef]

148. Koskilinna, J.O.; Linnolahti, M.; Pakkanen, T.A. Friction coefficient for hexagonal boron nitride surfaces from ab initio calculations. Tribol. Lett. 2006, 24, 37-41. [CrossRef]

149. Wang, J.; Wang, J.; Li, C.; Zhao, G.; Wang, X. A high-performance multifunctional lubricant additive for water-glycol hydraulic fluid. Tribol. Lett. 2011, 43, 235-245. [CrossRef]

150. Chen, B.; Bi, Q.; Yang, J.; Xia, Y.; Hao, J. Tribological properties of solid lubricants (graphite, h-BN) for Cu-based P/M friction composites. Tribol. Int. 2008, 41, 1145-1152. [CrossRef]

151. Tocci, G.; Joly, L.; Michaelides, A. Friction of water on graphene and hexagonal boron nitride from Ab initio methods: Very different slippage despite very similar interface structures. Nano Lett. 2014, 14, 6872-6877. [CrossRef]

152. Mahathanabodee, S.; Palathai, T.; Raadnui, S.; Tongsri, R.; Sombatsompop, N. Effects of hexagonal boron nitride and sintering temperature on mechanical and tribological properties of SS316L/h-BN composites. Mater. Des. 2013, 46, 588-597. [CrossRef]

153. Du, M.; Bi, J.Q.; Wang, W.L.; Sun, X.L.; Long, N.N. Influence of sintering temperature on microstructure and properties of $\mathrm{SiO}_{2}$ ceramic incorporated with boron nitride nanotubes. Mater. Sci. Eng. A 2012, 543, 271-276. [CrossRef]

154. Mahathanabodee, S.; Palathai, T.; Raadnui, S.; Tongsri, R.; Sombatsompop, N. Effect of h-BN content on the sintering of SS316L/h-BN Composites. Adv. Mater. Res. 2011, 410, 216-219. [CrossRef] 
155. Avril, L.; Courant, B.; Hantzpergue, J.J. Tribological performance of $\alpha$-Fe(Cr)-Fe 2 B-FeB and $\alpha-\mathrm{Fe}(\mathrm{Cr})-\mathrm{h}-\mathrm{BN}$ coatings obtained by laser melting. Wear 2006, 260, 351-360. [CrossRef]

156. Miyake, S.; Wang, M. Deposition and Tribology of Carbon and Boron Nitride Nanoperiod Multilayer Hard and Solid Lubricating Films. New Tribol. Ways 2011, 1, 71-88.

157. Mahathanabodee, S.; Palathai, T.; Raadnui, S.; Tongsri, R.; Sombatsompop, N. Dry sliding wear behavior of SS316L composites containing h-BN and $\mathrm{MoS}_{2}$ solid lubricants. Wear 2014, 316, 37-48. [CrossRef]

158. Miyake, S.; Hashizume, T.; Kurosaka, W.; Sakurai, M.; Wang, M. Deposition and tribology of carbon and boron nitride nanoperiod multilayer solid lubricating films. Surf. Coat. Technol. 2007, 202, 1023-1028. [CrossRef]

159. Chen, Z.; Li, H.; Fu, Q.; Qiang, X. Tribological behaviors of SiC/h-BN composite coating at elevated temperatures. Tribol. Int. 2012, 56, 58-65.

160. Tyagi, R.; Xiong, D.; Li, J. Effect of load and sliding speed on friction and wear behavior of silver/h-BN containing Ni-base P/M composites. Wear 2011, 270, 423-430. [CrossRef]

161. Tyagi, R.; Xiong, D.S.; Li, J.L.; Dai, J. High-temperature friction and wear of Ag/h-BN-containing Ni-based composites against steel. Tribol. Lett. 2010, 40, 181-186. [CrossRef]

162. Deshmukh, P.; Lovell, M.; Sawyer, W.G.; Mobley, A. On the friction and wear performance of boric acid lubricant combinations in extended duration operations. Wear 2006, 260, 1295-1304. [CrossRef]

163. Lovell, M.R.; Kabir, M.A.; Menezes, P.L.; Higgs, C.F. Influence of boric acid additive size on green lubricant performance. Philos. Trans. R. Soc. A Math. Phys. Eng. Sci. 2010, 368, 4851-4868. [CrossRef] [PubMed]

164. Kabir, M.A.; Higgs, C.F.; Lovell, M.R. A pin-on-disk experimental study on a green particulate-fluid lubricant. J. Tribol. 2008, 130, 041801. [CrossRef]

165. Uzoma, P.C.; Hu, H.; Khadem, M.; Penkov, O.V. Tribology of 2D Nanomaterials: A Review. Coatings 2020, 10, 897. [CrossRef]

166. Liu, H.; Du, Y.; Deng, Y.; Ye, P.D. Semiconducting black phosphorus: Synthesis, transport properties and electronic applications. Chem. Soc. Rev. 2015, 44, 2732-2743. [CrossRef]

167. Guo, P.; Qi, S.; Chen, L.; Gou, C.; Lin, B.; Lu, Z.; Zhang, G. Black Phosphorus-Graphene Oxide Hybrid Nanomaterials toward Advanced Lubricating Properties under Water. Adv. Mater. Interf. 2019, 6, 1901174. [CrossRef]

168. Wang, W.; Xie, G.; Luo, J. Black phosphorus as a new lubricant. Friction 2018, 6, 116-142. [CrossRef]

169. Lv, Y.; Wang, W.; Xie, G.; Luo, J. Self-Lubricating PTFE-Based Composites with Black Phosphorus Nanosheets. Tribol. Lett. 2018, 66, 1-11. [CrossRef]

170. Peng, S.; Guo, Y.; Xie, G.; Luo, J. Tribological behavior of polytetrafluoroethylene coating reinforced with black phosphorus nanoparticles. Appl. Surf. Sci. 2018, 441, 670-677. [CrossRef]

171. Erdemir, A.; Fenske, G.R.; Erck, R.A.; Nichols, F.A.; Busch, D.E. Tribological properties of boric acid and boric-acid-forming surfaces. Part II. Mechanisms of formation and self-lubrication of boric acid films on boron-and boric oxide-containing surfaces. Lubr. Eng. 1991, 47, 179-184.

172. Jayatissa, A.H.; Ahmed, O.; Manu, B.R.; Schroeder, A.M. Tribological Behaviour of Sputter Coated ZnO Thin Films. Prog. Mater. Sci. 2021, 3, 1-13.

173. Wang, Y.; Liua, Z. Tribological properties of high temperature self-lubrication metal ceramics with an interpenetrating network. Wear 2008, 265, 1720-1726. [CrossRef]

174. Prasad, S.V.; Zabinski, J.S. Tribological behavior of nanocrystalline zinc oxide films. Wear 1997, 203, 498-506. [CrossRef]

175. Jayatissa, A.H.; Manu, B.R. Tribological Properties at the Interface of the Aluminum and Aluminum Oxide. J. Multidisciplinary Eng. Sci. St. (JMESS) 2019, 5, 2595-2599.

176. Karch, J.; Birringer, R.; Gleiter, H. Ceramics ductile at low temperature. Nature 1987, 330, 556-558. [CrossRef]

177. Gardos, M.N. The effect of anion vacancies on the tribological properties of rutile (Ti0 $\left.0_{2-x}\right)$. Tribol. Trans. 1988, 31, 427-436. [CrossRef]

178. Goto, S.; Fujimura, N.; Nishihara, T.; Ito, T. Heteroepitaxy of zinc oxide thin films, considering non-epitaxial preferential orientation. J. Cryst. Growth. 1991, 115, 816-820. [CrossRef]

179. Goto, M.; Kasahara, A.; Tosa, M. Low-friction coatings of zinc oxide synthesized by optimization of crystal preferred orientation. Tribol. Lett. 2011, 43, 155-162. [CrossRef]

180. Venkatraman, R.; Bravman, J.C. Separation of film thickness and grain boundary strengthening effects in Al thin films on Si. J. Mater. Res. 1992, 7, 2040-2048. [CrossRef]

181. Zhu, Y.C.; Yukimura, K.; Ding, C.X.; Zhang, P.Y. Tribological properties of nanostructured and conventional WC-Co coatings deposited by plasma spraying. Thin Solid Films. 2001, 388, 277-282. [CrossRef]

182. Ramesh, C.S.; Noor Ahmed, R.; Mujeebu, M.A.; Abdullah, M.Z. Fabrication and study on tribological characteristics of cast copper-TiO 2 -boric acid hybrid composites. Mater. Des. 2009, 30, 1632-1637. [CrossRef]

183. Prasad, S.V.; Asthana, R. Aluminum metal-matrix composites for automotive applications: Tribological considerations. Tribol. Lett. 2004, 17, 445-453. [CrossRef]

184. Li, D.X.; You, Y.L.; Deng, X.; Li, W.J.; Xie, Y. Tribological properties of solid lubricants filled glass fiber reinforced polyamide 6 composites. Mater. Des. 2013, 46, 809-815. [CrossRef]

185. You, Y.L.; Li, D.X.; Si, G.J.; Deng, X. Investigation of the influence of solid lubricants on the tribological properties of polyamide 6 nanocomposites. Wear 2014, 311, 57-64. [CrossRef] 
186. Moser, J.; Lévy, F.; Bussy, F. Composition and growth mode of MoSx sputtered films. J. Vac. Sci. Tech. A Vac. Surf. Film. 1994, 12, 494-500. [CrossRef]

187. Veiga, C.; Davim, J.P.; Loureiro, A.J.R. Properties and applications of titanium alloys: A brief review. Rev. Adv. Mat. Sci. 2012, 32, 133-148.

188. Engler, O.; Hirsch, J. Texture control by thermomechanical processing of AA6xxx Al-Mg-Si sheet alloys for automotive applications -a review. Mater. Sci. Eng. A. 2002, 336, 249-262. [CrossRef]

189. Merie, V.V.; Cândea, V.C.; Bîrleanu, C.; Păşcuţă, P.; Popa, C.O. The influence of titanium dioxide on the tribological characteristics of a Fe-based friction composite material. J. Compos. Mater. 2014, 48, 235-243. [CrossRef]

190. Quazi, M.M.; Ishak, M.; Arslan, A.; Fazal, M.A.; Yusof, F.; Sazzad, B.S.; Nasir Bashir, M.; Jamshaid, M. Mechanical and tribological performance of a hybrid MMC coating deposited on Al-17Si piston alloy by laser composite surfacing technique. RSC Adv. 2018, 8, 6858-6869. [CrossRef]

191. Dorri Moghadam, A.; Omrani, E.; Menezes, P.L.; Rohatgi, P.K. Mechanical and tribological properties of self-lubricating metal matrix nanocomposites reinforced by carbon nanotubes (CNTs) and graphene-A review. Compos. Part B Eng. 2015, 77, 402-420. [CrossRef]

192. Menezes, P.L.; Rohatgi, P.K.; Omrani, E. Self-Lubricating Composites; Springer Sci. Bus: Berlin, Germany, 2018.

193. Popescu, I.N.; Ghiţă, C.; Bratu, V.; Palacios Navarro, G. Tribological behavior and statistical experimental design of sintered iron-copper based composites. Appl. Surf. Sci. 2013, 285, 72-85. [CrossRef]

194. Shu-xian, C.; Yi, F.; Shu, L.; Yu-juan, X. Influences of $\mathrm{MoS}_{2}$ contents on sintering process and properties of Cu-MoS 2 composites. J. Mat. Sci. Eng. 2008, 2, 7-12.

195. Kato, H.; Takama, M.; Iwai, Y.; Washida, K.; Sasaki, Y. Wear and mechanical properties of sintered copper-tin composites containing graphite or molybdenum disulfide. Wear 2003, 255, 573-578. [CrossRef]

196. Watanabe, Y. High-speed sliding characteristics of Cu-Sn-based composite materials containing lamellar solid lubricants by contact resistance studies. Wear 2008, 264, 624-631. [CrossRef]

197. Kovalchenko, A.M.; Fushchich, O.I.; Danyluk, S. The tribological properties and mechanism of wear of Cu-based sintered powder materials containing molybdenum disulfide and molybdenum diselenite under unlubricated sliding against copper. Wear 2012, 290, 106-123. [CrossRef]

198. Chandrasekaran, M.; Singh, P. Sintered iron-copper-tin-lead antifriction materials -effect of temperature. Mater. Sci. Eng. A. 2000, 292, 26-33. [CrossRef]

199. Teisanu, C.; Gheorghe, S. Development of new PM iron-based materials for self-lubricating bearings. Adv. Tribol. 2011, 2011, 1-11. [CrossRef]

200. Dhanasekaran, S.; Gnanamoorthy, R. Abrasive wear behavior of sintered steels prepared with $\mathrm{MoS}_{2}$ addition. Wear 2007, 262, 617-623. [CrossRef]

201. Dhanasekaran, S.; Gnanamoorthy, R. Microstructure, strength and tribological behavior of Fe-C-Cu-Ni sintered steels prepared with $\mathrm{MoS}_{2}$ addition. J. Mater. Sci. 2007, 42, 4659-4666. [CrossRef]

202. Xue, M. High temperature oxidation and wear behavior of powder metallurgically developed Ni-Cr-W-Al-Ti-MoS 2 composite. Indian J. Eng. Mater. Sci. 2009, 16, 111-115.

203. Li, J.L.; Xiong, D.S.; Huo, M.F. Friction and wear properties of Ni-Cr-W-Al-Ti-MoS 2 at elevated temperatures and self-consumption phenomena. Wear 2008, 265, 566-575. [CrossRef]

204. Shia, X.; Zhaia, W.; Wang, M.; Xu, Z.; Yao, J.; Song, S.; Wang, Y. Synergetic lubricating effect of $\mathrm{MoS}_{2}$ and $\mathrm{Ti}_{3} \mathrm{SiC}_{2}$ on tribological properties of NiAl matrix self-lubricating composites over a wide temperature range. Mater. Des. 2014, 55, 93-103. [CrossRef]

205. Shia, X.; Zhaia, W.; Wang, M.; Xu, Z.; Yao, J.; Song, S.; Wang, Y. Tribological behaviors of NiAl based self-lubricating composites containing different solid lubricants at elevated temperatures. Wear 2014, 310, 1-11. [CrossRef]

206. Li, J.L.; Xiong, D.S. Tribological properties of nickel-based self-lubricating composite at elevated temperature and counter face material selection. Wear 2008, 265, 533-539. [CrossRef]

207. Volochko, A.T.; Rumyantseva, I.N. Thermal stability of aluminum composite materials containing sulfides of copper, molybdenum, and zinc. Sov. Powder Metall. Met. Ceram. 1992, 31, 446-448. [CrossRef]

208. Xu, Z.; Shi, X.; Zhang, Q.; Zhai, W.; Li, X.; Yao, J.; Chen, L.; Zhu, Q.; Xiaov, Y. Effect of sliding speed and applied load on dry sliding tribological performance of TiAl matrix Self-Lubricating composites. Tribol. Lett. 2014, 55, 393-404. [CrossRef]

209. Li, S.; Feng, Y.; Yang, X.; Chen, S.; Wang, J. Structure and formation mechanism of surface film of Ag-MoS 2 composite during electrical sliding Wear. Mater. Eng. 2009, 38, 1881-1885.

210. Chen, F.; Feng, Y.; Shao, H.; Zhang, X.; Chen, J.; Chen, N. Friction and wear behaviors of Ag/MoS $/$ G composite in different atmospheres and at different temperatures. Tribol. Lett. 2012, 47, 139-148. [CrossRef]

211. Ouyang, J.H.; Li, Y.F.; Wang, Y.M.; Zhou, Y.; Murakami, T.; Sasaki, S. Microstructure and tribological properties of $\mathrm{ZrO}_{2}\left(\mathrm{Y}_{2} \mathrm{O}_{3}\right)$ matrix composites doped with different solid lubricants from room temperature to $800{ }^{\circ} \mathrm{C}$. Wear 2009, 267, 1353-1360. [CrossRef]

212. Jin, Y.; Kato, K.; Umehara, N. Tribological properties of self-lubricating $\mathrm{CMC} / \mathrm{Al}_{2} \mathrm{O}_{3}$ pairs at high temperature in air. Tribol. Lett. 1998, 4, 243-250. [CrossRef]

213. Jianxin, D.; Tongkun, C.; Zeliang, D.; Jianhua, L.; Junlong, S.; Jinlong, Z. Tribological behaviors of hot-pressed $\mathrm{Al}_{2} \mathrm{O}_{3} / \mathrm{TiC}$ ceramic composites with the additions of $\mathrm{CaF}_{2}$ solid lubricants. J. Eur. Ceram. Soc. 2006, 26, 1317-1323. [CrossRef] 
214. De Mello, J.D.B.; Binder, C.; Binder, R.; Klein, A.N. Effect of precursor content and sintering temperature on the scuffing resistance of sintered self-lubricating steel. Wear 2011, 271, 1862-1867. [CrossRef]

215. Li, B.; Liu, Y.; Li, J.; Cao, H.; He, L. Effect of sintering process on the microstructures and properties of in situ TiB $\mathrm{T}_{2}-\mathrm{TiC}_{\mathrm{C}}$ reinforced steel matrix composites produced by spark plasma sintering. J. Mater. Process. Technol. 2010, 210, 91-95. [CrossRef]

216. Friedrich, K.; Lu, Z.; Hager, A.M. Recent advances in polymer composites' tribology. Wear 1995, 190, 139-144. [CrossRef]

217. Potts, J.R.; Dreyer, D.R.; Bielawski, C.W.; Ruoff, R.S. Graphene-based polymer nanocomposites. Polymer 2011, 53, 5-25. [CrossRef]

218. Stankovich, S.; Dikin, D.A.; Dommett, G.H.B.; Kohlhaas, K.M.; Zimney, E.J.; Stach, E.A.; Piner, R.D.; Nguyen, S.T.; Ruoff, R.S. Graphene-based composite materials. Nature 2006, 442, 282-286. [CrossRef]

219. Kuilla, T.; Bhadra, S.; Yao, D.; Kim, N.H.; Bose, S.; Lee, J.H. Recent advances in graphene-based polymer composites. Prog. Polymer Sci. 2010, 35, 1350-1375. [CrossRef]

220. Wang, H.; Chang, L.; Yang, X.; Yuan, L.; Ye, L.; Harris, A.T.; Minett, A.I.; Trimby, P.; Friedrich, K. Anisotropy in tribological performances of long aligned carbon nanotubes/polymer composites. Carbon 2014, 67, 38-47. [CrossRef]

221. Gardos, M.N. Self-lubricating composites for extreme environment applications. Tribol. Int. 1982, 15, 273-283. [CrossRef]

222. Bijwe, J.; Logani, C.M.; Tewari, U.S. Influence of fillers and fiber reinforcement on abrasive wear resistance of some polymeric composites. Wear 1990, 138, 77-92. [CrossRef]

223. Davim, J.P. Ecotribology, 1st ed.; Springer Sci. Bus: Cham, Switzerland, 2016.

224. Tang, H.; Cao, K.; Wu, Q.; Li, C.; Yang, X.; Xuehua, Y. Synthesis and tribological properties of copper matrix solid self-lubricant composites reinforced with $\mathrm{NbSe}_{2}$ nanoparticles. Cryst. Res. Technol. 2011, 46, 195-200. [CrossRef]

225. Zhang, F.X.; Chu, Y.Q.; Li, C.S. Fabrication and tribological properties of copper matrix solid self-lubricant composites reinforced with $\mathrm{Ni} / \mathrm{NbSe}_{2}$ composites. Materials 2019, 12, 1854. [CrossRef]

226. Sundararajan, S.; Rajadurai, J.S.; Antony Vasanthakumar, C. Impact of solid self-lubricant and hard ceramic reinforcements on tribological characteristics of microwave-sintered $\mathrm{Cu}$ hybrid composites processed by solid-state mixing technique. Proc. Inst. Mech. Eng. Part J J. Eng. Tribol. 2017, 231, 523-542. [CrossRef]

227. Prabhu, T.R. Effects of solid lubricants, load, and sliding speed on the tribological behavior of silica reinforced composites using design of experiments. Mater. Des. 2015, 77, 149-160. [CrossRef]

228. Zhen, J.; Zhu, S.; Cheng, J.; Li, M.; Lu, Y.; Qia, Z.; Yang, J. Influence of graphite content on the dry sliding behavior of nickel alloy matrix solid lubricant composites. Tribol. Int. 2017, 114, 322-328. [CrossRef]

229. Zhao, Y.; Feng, K.; Yao, C.; Nie, P.; Huang, J.; Li, Z. Microstructure and tribological properties of laser cladded self-lubricating nickel-base composite coatings containing nano-Cu and h-BN solid lubricants. Surf. Coat. Technol. 2019, 359, 485-494. [CrossRef]

230. Chen, B.; Zhang, J.; Jia, J.; Hu, W.; Gong, C. Tribological properties of solid lubricants (graphite, MoS 2 ) for Ni based materials IOP Conf. Ser. Earth Environ. Sci. 2018, 186, 012030. [CrossRef]

231. Yang Huang, X.; Wang, J.; Zhang, H.; Ren, J.; Zan, Q.; Gong, Q.; Wu, B. WC-Ni-Cr-based self-lubricating composites fabricated by pulsed electric current sintering with addition of $\mathrm{WS}_{2}$ solid lubricant. Int. J. Refract. Met. Hard Mater. 2017, 66, 158-162. [CrossRef]

232. Kotkowiak, M.; Piasecki, A.; Kulka, M. The influence of solid lubricant on tribological properties of sintered $\mathrm{Ni}^{-20} \% \mathrm{CaF}_{2}$ composite material. Ceram. Int. 2019, 45, 17103-17113. [CrossRef]

233. Gupta, A.; Mohan, S.; Anand, A.; Haq, M.I.U.; Raina, A.; Kumar, R.; Singh, R.A.; Jayalakshmi, S.; Kamal, M. Tribological behavior of Fe-C-Ni self-lubricating composites with $\mathrm{WS}_{2}$ solid lubricant. Mater. Res. Express 2019, 6, 126507. [CrossRef]

234. Zalaznik, M.; Kalin, M.; Novak, S.; Jakša, G. Effect of the type, size and concentration of solid lubricants on the tribological properties of the polymer PEEK. Wear 2016, 364, 31-39. [CrossRef]

235. Cura, M.E.; Kim, S.H.; Muukkonen, T.; Varjus, S.; Vaajoki, A.; Soderberg, O.; Suhonen, T.; Kanerva, U.; Lee, S.W.; Hannnula, S.P. Microstructure and tribological properties of pulsed electric current sintered alumina-zirconia nanocomposites with different solid lubricants. Ceram. Int. 2013, 39, 2093-2105. [CrossRef]

236. Ali, M.K.A.; Xianjun, H. M50 Matrix Sintered with Nanoscale Solid Lubricants Shows Enhanced Self-lubricating Properties Under Dry Sliding at Different Temperatures. Tribol. Lett. 2019, 67, 1-16. [CrossRef]

237. Li, T.; Tao, J.; Cong, P.; Liu, X. Study on the tribological characteristics of solid lubricants embedded tin-bronze bearings. J. Appl. Polym. Sci. 2001, 80, 2394-2399. [CrossRef]

238. Mushtaq, S.; Wani, M.F.; Nadeem, M.; Najar, K.A.; Mursaleen, M. A study on friction and wear characteristics of Fe-Cu-Sn alloy with $\mathrm{MoS}_{2}$ as solid lubricant under dry conditions. Sadhana 2019, 44, 1-7. [CrossRef] 